\title{
LA PERSISTENTE DEBILIDAD INSTITUCIONAL DE ECUADOR. Protestas, elecciones y divisiones políticas DURANTE el 2019
}

\author{
Ecuador's Persistent Institutional Weakness: Protests, Elections and \\ Political Divisions During 2019.
}

\section{ALEJANDRO OLIVARES}

Universidad Católica de Temuco, Chile

\section{PABLO MEDINA}

Facultad Latinoamericana de Ciencias Sociales, Ecuador

\begin{abstract}
RESUMEN
El presente artículo analiza los eventos políticos más relevantes del año 2019 en Ecuador. Al examinar el estilo de gobierno, condiciones económicas, las relaciones entre el ejecutivo y legislativo, se sostiene que el marco institucional es extremadamente dependiente del estilo de liderazgo del presidente y del contexto económico, particularmente de los precios del petróleo. Contrario a lo que se esperaba, la vigencia por más de diez años de la constitución no ha entregado valor a las instituciones, las protestas de octubre y los riesgos de ruptura del marco institucional así lo demuestran. Este caso, que sirve de ejemplo para comprender los efectos de la debilidad presidencial sobre la gobernabilidad, permite ver la influencia del contexto económico y político sobre la fortaleza de las instituciones y, en última instancia, sobre la democracia en la región latinoamericana.
\end{abstract}

Palabras Clave: Ecuador, instituciones, protesta, Correísmo.

\begin{abstract}
This article analyzes the main political events of 2019 in Ecuador. By examining the style of government, economic conditions, relations between the executive and the legislature, it is argued that the institutional framework is extremely dependent on the president's leadership style and the economic context, particularly on oil prices. Contrary to what was expected, the validity for more than ten years of the constitution has not strengthened institutions, the October protests and the risks of rupture of the institutional framework demonstrate this. This case, which serves as an example to understand the effects of presidential weakness on governance, allows us to see the influence of the economic and political context on the strength of institutions and, ultimately, on democracy in the Latin American region.
\end{abstract}

Keywords: Ecuador, institutions, protest, Correísmo. 


\section{INTRODUCCIÓN ${ }^{1}$}

El martes $1^{\circ}$ de octubre de 2019, en una cadena nacional, el presidente de Ecuador, Lenin Moreno, anunciaba que mediante el Decreto Presidencial N ${ }^{\circ} 883$ se establecía una serie de reformas económicas y laborales destinadas a reducir el gasto público ${ }^{2}$. La principal medida adoptada por el ejecutivo consistía en la eliminación del subsidio a los combustibles (gasolina y diésel), vigente desde la década del 70 .

El paquete de reformas, que en gran medida era resultado de la negociación con el Fondo Monetario Internacional (FMI) ${ }^{3}$ generó opiniones encontradas en la sociedad. Fue apoyado por "expertos y académicos que lo calificaron como duro, pero realista y necesario para corregir los grandes vicios de la economía ecuatoriana" (Barragán et al. 2020: 210). No obstante, en la sociedad civil, la eliminación del subsidio generó gran malestar y fue el catalizador de importantes protestas. Retomando una larga tradición de movilización, diversos sectores de la población rápidamente se congregaron contra el gobierno y llamaron a protestas, huelgas, tomas de espacios públicos y cierre de carreteras. Estas acciones tuvieron, durante once días, al gobierno bajo mucha presión, obligándolo después de una mesa de negociación televisada a todo el país, a retirar el decreto, como pedían los manifestantes.

Los once días de protesta dejaron en evidencia que los movimientos sociales, especialmente el movimiento indígena, volvían a ser un actor capaz de articular demandas y movilizar a sus bases (Altmann 2020) y por lo mismo a ser un actor relevante en la política nacional. La movilización también dio cuenta de la importante politización y polarización ideológica de la población ecuatoriana durante la última década (Moncagatta y Poveda 2020). Del mismo modo, quedó en evidencia que la estabilidad institucional (luego de once años de vigencia de la última constitución) era solo un espejismo ya que el sistema político en general, y el gobierno de Moreno en particular, no poseen capacidad para procesar los conflictos políticos y deben ceder ante las presiones organizadas. En este contexto, el presente artículo entrega un análisis del año 2019 del gobierno de Lenin Moreno en Ecuador.

Sostenemos que el 2019 marca un punto de inflexión en la política reciente de Ecuador, ya que queda en evidencia la debilidad de sus instituciones políticas. Aunque siempre fueron débiles, el estilo de Rafael Correa (antecesor de Moreno) ocultaba parcialmente esa debilidad. En general, en el periodo anterior de gobierno, los problemas de corrupción, las crisis políticas y los déficits estatales, se solucionaban con un fuerte liderazgo presidencial, sostenido por un

\footnotetext{
Los autores agradecen a Camila Carrasco H., Isabel Miranda O., Emilia Parreño, José Zurita, Gustavo Pérez, Anabel Yanes y Sergio Huertas por su ayuda en la preparación de este trabajo.

El decreto está disponible en la siguiente nota de prensa: https://www.elcomercio.com/actualidad/decreto-alza-gasolinas-diesel-subsidios.html

Para detalles del acuerdo ver FMI (2019a).
} 
amplio apoyo popular y un importante gasto público (Freidenberg y Pachano 2016), lo cual Moreno no ha podido replicar por no contar con recursos para gastar, ni apoyo popular, ni contingente legislativo.

El artículo está estructurado de la siguiente manera: en la primera parte se presentan algunas reflexiones sobre los poderes ejecutivo y legislativo, dando énfasis en la rotación de ministros, así como los problemas del gobierno para la conformación de las mayorías legislativas, ambos antecedentes claros de la falta de liderazgo del gobierno. En la segunda parte, se analiza la protesta de octubre de 2019, las estrategias de los principales actores y el desarrollo de los eventos. Por último, se examinan algunos elementos institucionales, dando especial énfasis a los problemas de la puesta en régimen del Consejo de Participación Ciudadana y Control Social (CPCCS), y se discuten los resultados de las elecciones parroquiales, municipales y provinciales realizadas en el mes de marzo. Para finalizar se presentan las principales conclusiones de este artículo que dan cuenta de que, pese a que las instituciones formales relativas al poder del presidente se mantienen constantes con respecto a los periodos gubernamentales anteriores, factores contextuales como el estado de la economía y el estilo de gobierno muestran la frágil institucionalización política del Ecuador.

\section{EL EJECUTIVO Y LEGISLATIVO EN ECUADOR DURANTE EL 2019}

La literatura sobre presidencialismo ha tenido diferentes olas de investigación a lo largo de los últimos años. En ellas, el debate sobre el hiperpresidencialismo ha jugado un rol importante (Basabe-Serrano 2017), ya que la elección de presidentes fuertes en Venezuela, Bolivia y Ecuador dio un contexto particular para su desarrollo. En este debate, alguna literatura ha ubicado a Ecuador, por la capacidad del presidente de controlar el ordenamiento jurídico y por la concentración de poderes en su figura, como un caso de hiperpresidencialismo (Guerrero 2018; Ortiz 2018). No obstante, cuando consideramos además tanto los poderes formales del presidente como algunos elementos contextuales como la popularidad de la que goza el mandatario y la situación económica del país) (Basabe-Serrano 2017), la interpretación sobre Ecuador puede variar.

Tal como señalan Arévalo y Basabe-Serrano (2017: 393) cuando se incorporan otras lógicas más allá de los poderes normativos, se confirma que Ecuador está por bajo la media regional de poderes presidenciales "con lo que la idea de que el diseño institucional de este país es de los más presidencialistas de América Latina queda en entredicho" (2017: 393). En este trabajo, considerando que el diseño institucional del poder ejecutivo no ha cambiado desde el año 2012, ${ }^{4}$ nos concentramos en los elementos contextuales a los que se refiere Basabe-Serrano (2017). Para ello, en la tabla 1, actualizamos los datos presentados por el autor

Las modificaciones realizadas vía enmienda constitucional en 2015 fueron anuladas en el año 2018 por Sentencia de la Corte Constitucional. 
utilizando las mismas fuentes de datos de su trabajo, el índice de popularidad reportado por la Firma Mitofsky y el ingreso per cápita, como proxy de la situación económica del país, reportado por el Informe de Competitividad del Foro Económico Mundial 5 .

Tabla 1. Poder contextual del presidente en América Latina

\begin{tabular}{|c|c|c|c|c|c|c|c|c|c|c|}
\hline \multirow{2}{*}{ País } & \multicolumn{3}{|c|}{2012} & \multicolumn{3}{|c|}{2019} & \multirow{2}{*}{ Diferencia } & \multicolumn{3}{|c|}{ Ranking } \\
\hline & Popularidad & Economía & Total & Popularidad & Economía & Total & & 2012 & 2019 & Diferencia \\
\hline Argentina & 0.54 & 0.76 & 1.30 & 0.71 & 0.68 & 1.39 & 0.09 & 7 & 2 & 5 \\
\hline Bolivia & 0.51 & 0.15 & 0.66 & 0.54 & 0.21 & 0.75 & 0.09 & 17 & 12 & 5 \\
\hline Brasil & 0.78 & 0.9 & 1.68 & 0.36 & 0.52 & 0.88 & -0.80 & 1 & 11 & -10 \\
\hline Chile & 0.45 & 0.99 & 1.44 & 0.40 & 0.94 & 1.34 & -0.10 & 4 & 5 & -1 \\
\hline Colombia & 0.68 & 0.52 & 1.20 & 0.36 & 0.39 & 0.75 & -0.45 & 10 & 13 & -3 \\
\hline Costa Rica & 0.16 & 0.65 & 0.81 & 0.26 & 0.68 & 0.95 & 0.14 & 15 & 10 & 5 \\
\hline Ecuador & 1 & 0.33 & 1.33 & 0.28 & 0.37 & 0.64 & -0.69 & 6 & 15 & -9 \\
\hline El Salvador & 0.9 & 0.31 & 1.21 & 1.00 & 0.23 & 1.23 & 0.02 & 9 & 6 & 3 \\
\hline Guatemala & 0.86 & 0.24 & 1.10 & 0.70 & 0.27 & 0.97 & -0.13 & 12 & 9 & 3 \\
\hline Honduras & 0.18 & 0.17 & 0.35 & 0.41 & 0.15 & 0.56 & 0.21 & 18 & 16 & 2 \\
\hline México & 0.59 & 0.8 & 1.39 & 0.80 & 0.57 & 1.37 & -0.02 & 5 & 3 & 2 \\
\hline Nicaragua & 0.74 & 0.09 & 0.83 & 0.30 & 0.12 & 0.42 & -0.41 & 14 & 17 & -3 \\
\hline Panamá & 0.65 & 0.63 & 1.28 & 0.59 & 0.91 & 1.50 & 0.22 & 8 & 1 & 7 \\
\hline Paraguay & 0.45 & 0.24 & 0.69 & 0.39 & 0.34 & 0.73 & 0.04 & 16 & 14 & 2 \\
\hline Perú & 0.5 & 0.43 & 0.93 & 0.65 & 0.41 & 1.06 & 0.13 & 13 & 8 & 5 \\
\hline $\begin{array}{l}\text { R. } \\
\text { Dominicana }\end{array}$ & 0.76 & 0.44 & 1.20 & 0.68 & 0.46 & 1.13 & -0.07 & 11 & 7 & 4 \\
\hline Uruguay & 0.5 & 1 & 1.50 & 0.35 & 1.00 & 1.35 & -0.15 & 3 & 4 & -1 \\
\hline Venezuela & 0.8 & 0.83 & 1.63 & 0.16 & 0.20 & 0.36 & -1.27 & 2 & 18 & -16 \\
\hline
\end{tabular}

Elaboración propia. Fuente de datos: Basabe-Serrano (2017); The Global Competitiveness Report (2019); Consulta Mitofsky (2020)

En comparación con el año 2012 (en que Basabe-Serrano realiza su trabajo), el año 2019 observamos que Ecuador, en materia de poderes contextuales del presidente, cayó nueve lugares, del sexto lugar en el que se encontraba en 2012 al décimo quinto en el que se ubica en 2019. Esta diferencia es relevante ya que, si como se mencionó previamente, el marco institucional formal no ha cambiado en lo que concierne a los poderes del presidente, esta diferencia de contexto podría en parte explicar la crisis de gobernabilidad con la que el país concluyó el año 2019. Es por esto, que a continuación analizamos parte del liderazgo del presidente Moreno, dando especial énfasis a sus decisiones políticas, especialmente, sus nombramientos y relación con el legislativo, para más adelante referirnos al contexto económico. 


\section{El poder ejecutivo}

Para comprender el accionar del ejecutivo durante el año 2019 es importante considerar algunos aspectos previos que inciden en la lógica del funcionamiento del gobierno. La presidencia de Lenin Moreno, iniciada el 24 de mayo de 2017, debió rápidamente enfrentar una serie de problemas sociales, políticos y económicos derivados en gran medida del fin del boom del precio del petróleo, los altos niveles de endeudamiento fiscal, las acusaciones de corrupción contra líderes de su partido (Alianza País) y la separación con Rafael Correa.

Si bien la relación entre el actual presidente y su antecesor se rompió durante el 2017, los efectos de esa separación son visibles en el 2018. Durante ese año Moreno utilizó una estrategia discursiva en la cual responsabilizaba a su antecesor de todos los problemas del país, tomando partido por el grupo anti-Correa, división fundamental sobre la que se estructura mayoritariamente la política ecuatoriana desde el 2007. Esta retórica, además de permitirle marcar una separación de estilos e implementar políticas muy diferentes a las de su antecesor, también permitió al presidente separar paulatinamente de sus cargos a los seguidores de Correa que aún formaban parte del gobierno (entre otros cargos de alta visibilidad, el correísmo contaba con ministros, subsecretarios, superintendentes y otros puestos relevantes en el estado).

En el 2019, ya sin el correísmo en los primeros puestos del gobierno, el presidente Moreno demostró su estilo de gestión y terminó de definir su posición política. Esto se puede ver en al menos dos elementos. En primer lugar, el presidente confirma su posición en el debate que ha articulado en los últimos años la política ecuatoriana: la polarización correísmo/anticorreísmo, ubicándose en cuadrante del anticorreísmo ${ }^{6}$. En segundo lugar, los cargos de la primera línea quedaron en manos de tecnócratas y outsiders. Entonces, durante el 2019 es factible asumir que el gobierno y sus cuadros son "anticorreístas" con un discurso tecnócrata. Esto podría explicar en parte los problemas entre el gobierno y el poder legislativo.

La relación entre el poder ejecutivo y legislativo es problemática toda vez que el ejecutivo no cuenta con una bancada que pueda dar apoyo a sus iniciativas de política pública y, además, el gabinete ministerial posee pocas redes políticas. Esto resulta importante ya que, como ha confirmado parte de la literatura, las estrategias del presidente pueden estar determinadas por el apoyo que tenga en el congreso (Amorim Neto 2006; Toro 2007; Gamboa y Toro 2018). En este contexto, el nombramiento de los ministros (y también del vicepresidente) puede ser entendida como una acción estratégica del presidente que le permita asegurar el apoyo legislativo. De hecho, al inicio del gobierno, normalmente, los ministros se nombran para asegurar la implementación de las políticas definidas en el plan de gobierno (Amorim Neto 2006).

Esta polarización no se expresa necesariamente en temas sustantivos de política pública, economía o derechos, sino más bien en la estética y retórica del gobierno, o en lo que en este trabajo se identifica como estilo de gobierno. Para una revisión más detallada de este tema, ver Rodríguez (2020). 
Los ministros (y en este caso también el vicepresidente) son actores centrales en el funcionamiento del poder ejecutivo y en la definición de las políticas públicas, ya que "en la práctica, los gabinetes están conformados por el partido o conjunto de partidos que acompañan a los presidentes y es a través de sus ministros que se entienden con el Congreso" (Escudero y Gamboa 2017: 36).

\section{Los vicepresidentes de Moreno}

Los vicepresidentes, que tan poca atención ha recibido en la investigación académica, puede ser una pieza de evidencia fundamental para comprender las estrategias coyunturales y la toma de decisión del presidente. Además de ser el segundo al mando, es el reemplazo del presidente y está sujeto a las mismas condiciones de permanencia en el cargo que el presidente, lo que puede ser muy importante para la estabilidad del ejecutivo. ${ }^{7}$

En Ecuador, la vicepresidencia es prácticamente un ministerio más. Esto porque al igual que los ministros, el vicepresidente recibe mandatos o tareas a realizar mientras esta en funciones (la Vicepresidencia no tiene definidas funciones salvo es reemplazar al presidente). Al recibir un mandato presidencial, puede tener un activo rol político, social o de gestión, o simplemente ser el segundo mandatario y no hacer nada salvo esperar su turno para asumir como primer mandatario. Sostenemos que puede ser un cargo clave para construir y mantener una alianza política dado que una vez nombrado no puede ser removido a voluntad del primer mandatario (a diferencia de lo que ocurre con los ministros), sino que necesita de la aprobación del congreso.

En el caso del presidente Moreno, hasta el 2019 ha sido acompañado por tres vicepresidentes, cada uno con responsabilidades institucionales y con características personales distintas. El primero de ellos fue Jorge Glas, con la responsabilidad de conducir la reconstrucción de las provincias afectadas por el terremoto del 2016 (El Universo 2017). Glas es un político con tradición en el correísmo, a tal punto que fue el principal competidor de Moreno en la interna de Alianza País (AP) para ser el sucesor de Correa (Meléndez y Moncagatta 2017). Una vez que AP eligió a Moreno como candidato, probablemente a partir de los sondeos y resultados de encuestas, Glas asumió como su compañero de lista. Su inclusión en el binomio fue vista como una apuesta de Correa "por preservar influencia en la transición en ciernes" (Ramírez 2019: 20). Glas estuvo en el cargo hasta fines de 2017, cuando fue condenado a seis años de prisión por asociación ilícita (durante el gobierno de Correa) por sobornos de la constructora Odebrecht.

Como reemplazo de Glas, el presidente presentó a la Asamblea Nacional a quien fue ratificada en el cargo, María Alejandra Vicuña, militante de Alianza País. Vicuña, que hasta ese momento era Ministra de Desarrollo Urbano 
y Vivienda, estuvo en el cargo entre enero y diciembre de 2018. El presidente encargó a Vicuña continuar con las tareas de reconstrucción, la ejecución de la política gubernamental de economía popular, y la coordinación entre el gobierno y el Instituto Ecuatoriano de Seguridad Social (Decreto Ejecutivo No 333). La vicepresidenta debió dejar su cargo acusada de cobros indebidos a sus subalternos mientras fue congresista. El caso contra Vicuña, y otros congresistas, es conocido como "diezmos" y corresponde a una práctica de algunos asambleístas de cobrar a sus colaboradores parte del sueldo que la institución les pagaba. ${ }^{8}$ El descubrimiento de esta práctica llevaría a investigaciones de al menos 19 asambleístas por parte de la Fiscalía General del Estado (Vélez 2019a).

En diciembre de 2018 asumió como vicepresidente Otto Sonnenholzner. Un outsider a quien el presidente le asignó como tareas la generación de gobernabilidad por medio del desarrollo del "Diálogo Social Nacional"; la implementación de la Agenda para el Desarrollo Sostenible; atraer inversión extranjera y el acompañamiento de seis áreas estratégicas del gobierno (García 2018). El nuevo vicepresidente no es conocido entre las elites políticas, por ello y por su edad (asumió con 36 años), tiene escasa posibilidad de estar vinculado con actos de corrupción, lo que es un gran activo para el gobierno. La llegada del nuevo vicepresidente consolida un estilo presidencial donde destaca la poca presencia de partidos y movimientos en la primera línea de la toma de decisión del estado. Tal como veremos a continuación esto aplica también para los ministros.

\section{Los gabinetes de Moreno ${ }^{9}$}

La literatura reconoce que es factible considerar como una muestra del estilo del gobierno a los nombramientos en el gabinete (González-Bustamante y Olivares 2016). Usualmente, es el gabinete inicial el que mejor representa el estilo del presidente, ya que da información sobre sus prioridades y sobre la forma de trabajo que pretende desarrollar (Amorim Neto 2006). Del mismo modo, los gabinetes intermedios, pueden dar cuenta de los cambios estratégicos del gobierno (Olivares et al. 2015; Camerlo y Martínez-Gallardo 2018). Al ser una atribución exclusiva del presidente, este puede integrar a los gabinetes personas cercanas a su figura, sean militantes o no. Independiente de su perfil se espera que estos sean los responsables de las políticas públicas sectoriales.

Los ministros, desde su posición en el gabinete, son actores centrales en el funcionamiento del poder ejecutivo. Ellos son responsables de la implementación del programa de gobierno a partir del cumplimiento de las tareas de la cartera que les corresponde liderar. Por lo tanto, en gran medida, de los ministros depende el éxito de un gobierno. Si los ministros desarrollan bien su trabajo el gobierno será estable y exitoso, por el contrario, cuando los ministros no cumplen las metas y objetivos o cuando tienen problemas de alto nivel (como corrupción o escándalos), se transforman en un obstáculo para la gestión.

Vicuña fue condenada en enero de 2020 a un año de prisión por el caso diezmos (El Comercio 2020b).

Para un análisis sobre los gabinetes de Ecuador antes de Moreno recomendamos Basabe-Serrano et al. (2018) 
Siguiendo a Indridason y Bowler (2013), los gabinetes funcionan bien cuando se han coordinado las expectativas de los partidos políticos con el gobierno (recompensas esperadas) y se han coordinado las relaciones entre los partidos y los ministros, todo esto con el fin de que estos actores (ministros y partidos) cumplan los objetivos y las políticas del gobierno y no sus agendas particulares. En el otro extremo, cuando casi no hay partidos en el gabinete, como el caso de Ecuador bajo el gobierno de Moreno, los ministros responden solo al presidente, no hay intermediario y los intereses de los sujetos no son conocidos, pues no están mediados por estructura alguna (partido), como en nuestro caso a los ministros y al vicepresidente.

Desde el inicio del gobierno la presencia de los partidos en los gabinetes ha sido escaza. Los cinco partidos que han aportado con sus cuadros son Partido Socialista Ecuatoriano (un ministro), Fuerza Compromiso Social (un ministro), Ruptura 25 (dos ministros), Movimiento Centro Democrático (tres ministros); Alianza PAIS (5 ministros). La mayoría de los ministros que ha tenido Moreno (32 ministros) han sido son personas que no tienen militancia (ver anexo). Estos ministros, al igual que el actual vicepresidente, no tienen experiencia política y en algunos casos tienen credenciales académicas, es decir, son tecnócratas y outsiders. Que los gabinetes sean de ministros con este perfil puede ser considerado como un mecanismo del presidente para mantener autonomía ante los partidos (grupos) que lo apoyaron (Carreras 2013; Arana 2016). Lo anterior, se refiere a que los ministros militantes tienen responsabilidades duales, ya que tienen que cumplir no sólo ante el presidente que lo designó ministro, sino que también dar cuenta a su partido político que, probablemente, lo promovió como candidato para el cargo (Altman 2000). Por ello, cuando un presidente incorpora militantes en sus gabinetes estaría limitando unilateralmente su capacidad de actuar (Altman y Castiglioni 2008).

Si analizamos solo el gabinete en ejercicio, poniendo especial énfasis en los perfiles de los titulares de cada ministerio, se destaca el hecho de que el $41 \%$ corresponde a personas que tienen credenciales asociadas a tecnócratas (son economistas, empresarios e ingenieros). Del mismo modo, se evidencian varios perfiles especializados en el área del ministerio donde son titulares (un militar en defensa, en educación una Master of Arts Education, un médico en salud, un cantante en cultura, un arquitecto en desarrollo urbano). En todos estos casos, la presencia y mantención de los ministros en sus cargos se explica por su nivel de conocimiento "experto" en el área en cuestión. Otro asunto importante, es que solo el $24 \%$ de los ministros son abogados y poseen una trayectoria típicamente política.

Respecto a temas de género, Moreno mantiene la tendencia de los presidentes ecuatorianos de nombrar pocas mujeres en los ministerios (Sotomayor y Huertas 2017; Basabe-Serrano 2020) ${ }^{10}$. Del gabinete en ejercicio solo el 17,6\% 
son mujeres. Si consideramos todo el gobierno, la cifra mejora y llega al $20 \%$. No obstante, la inclusión de las mujeres en la esfera política sigue siendo una de las tareas pendientes en Ecuador. Quizás una gran diferencia con otros momentos de la historia reciente del país es que una de las mujeres del gabinete (María Paula Romo) es la titular del Ministerio de Gobierno, uno de los ministerios más importantes en términos políticos pues tiene como misión "afianzar la seguridad ciudadana y la convivencia social", por lo que, en el contexto del año 2019, año de las manifestaciones, jugó un rol central en la política nacional.

Un elemento que se destaca dentro del poder ejecutivo, es que durante el 2019 existe una definición ideológica clara por parte del gobierno. A pesar de ser electo con un discurso de izquierda, no tan radical como el de su antecesor, sus acciones lo tienden a ubicar progresivamente al centro del escenario político. Incluso para de la sociedad, este movimiento significa un giro a la derecha, y califican al gobierno no como centrista sino como derechista ya que, por su cercanía con las cámaras de comercio, el perfil tecnocrático de los ministros representaría mejor los intereses de las elites económicas que de los de otros sectores de la sociedad ecuatoriana (Chiasson-LeBel 2019).

En suma, el 2019 confirma un gobierno de perfil tecnocrático (por sus ministros y su vicepresidente), con un fuerte antagonismo con Correa, la despolitización (ya casi no quedan militantes en los cargos importantes) y la salida de la izquierda correísta de las estructuras del estado. Con todo, su intento de implementación de medidas de ajuste que generaron la movilización de octubre, marca el tránsito definitivo al centro. Queda por evaluar si se trata del movimiento final o si el gobierno continuara con su giro a la derecha. Estas acciones tienen como consecuencia que el presidente no cuenta con contingente legislativo. Su partido, en el cual milita, no es el partido de gobierno. Esto, como veremos en la próxima sección, tiene implicancias en la tramitación de leyes en la Asamblea Nacional.

\section{El legislativo}

Que el gobierno no tenga apoyo legislativo fue otra de las consecuencias de su ruptura con el correísmo y de la estrategia de gobierno de Moreno. En términos numéricos la agrupación política Alianza País, en la elección del 2017 obtuvo 74 de los 137 escaños de la Asamblea Nacional alcanzando escaños en 33 de los 35 distritos. Esto le aseguraba una mayoría en el parlamento unicameral de Ecuador y avizoraba un gobierno que no necesitaría coaliciones para desarrollar sus políticas. No obstante, tras la ruptura interna del partido a finales del 2017 (entre los grupos alineados con Correa y aquellos leales al presidente Moreno), la bancada parlamentaria de Alianza País (morenistas), se redujo a 40 curules lo que obligó al gobierno, por primera vez desde 2009, a la búsqueda acuerdos y al establecimiento de negociaciones inter partidarias para avanzar con su agenda legislativa. 
En Ecuador, los gobiernos de minoría eran una característica en todas las presidencias de la historia política más reciente del país. Desde el retorno a la democracia en 1979 hasta el $2013^{11}$ ningún presidente disfrutó de mayoría en el parlamento por lo que dependió de coaliciones para gobernar.

La evidencia demuestra dos momentos en la estructuración de las coaliciones legislativas en el Ecuador (Mejía Acosta 2006; Mejía Acosta y Polga-Hecimovich 2011). Un primer momento ocurre entre 1979 y 1996, en donde las coaliciones duraron un promedio de 12 meses y el ejecutivo cuenta con una serie de herramientas que le permiten asegurar el apoyo legislativo para avanzar con su agenda política. Estas herramientas consisten en diferentes medios de transferencia de recursos a los parlamentarios como asignaciones presupuestarias para la ejecución de obras en sus distritos electorales, uso de gastos reservados (normalmente diseñados para el uso en materia de seguridad y defensa y no auditados) para sobornos, entre otros. La lógica anterior, le permite establecer alianzas que, aunque siempre puntuales y normalmente clandestinas, contribuyen a la gobernabilidad de ese periodo.

Un segundo momento entre 1996 y 2006, tras las reformas políticas de la época, las coaliciones disminuyeron su duración promedio a 3,32 meses (Mejía Acosta y Polga-Hecimovich 2011). Tras la acusación del entonces vicepresidente de la República Alberto Dahik en 1995, por uso de fondos reservados para el establecimiento de esas "coaliciones fantasmas", se establecen una serie de reformas que culminarían en 1998 con la redacción de una nueva constitución, en las que se limita el uso de fondos reservados al ejecutivo y se eliminan las partidas presupuestarias asignadas a los legisladores. Este nuevo escenario, si bien pudo haber disminuido la "compra de votos" en el parlamento, dificultó la estructuración de coaliciones lo que generaría múltiples bloqueos a causa del conflicto entre ejecutivo y legislativo (Mejía Acosta 2006; Mejía Acosta y Polga-Hecimovich 2011).

Con la Constitución de 2008, las condiciones de 1998 se mantienen e incluso se endurecen ampliando la definición penal del tráfico de influencias y prohibiendo expresamente el manejo de fondos públicos por parte de los legisladores; sin embargo, el éxito electoral de Alianza País le aseguró una cuasi mayoría en el período legislativo de 2009-2013, faltándole únicamente 4 votos, y una amplísima mayoría de 100 de 137 asambleístas (sin contar eventuales aliados) entre 2013 y 2017. Durante los 10 años de gobierno de Alianza País, no hubo necesidad de establecer negociaciones de gran calibre en el parlamento, de hecho, gracias a su control del ejecutivo y legislativo, contaba con un mecanismo informal conocido como "el hexágono", a través del que el ejecutivo aseguraba

11 En el periodo correísta de 2009 a 2013 el presidente contó con 59 de los 63 votos que necesitaba en la primera legislatura de la Asamblea Nacional bajo la Constitución de 2008. Si bien, siempre contó con estos votos gracias a alianzas con independientes o por los votos de otros movimientos de izquierda, por lo que no requirió mayores esfuerzos de negociación en el legislativo, estrictamente tampoco Correa contó con una mayoría parlamentaria en este período. 
la disciplina de sus legisladores, ${ }^{12}$ bajo la amenaza velada de sanciones no solo partidarias, sino en su futuro político. Sin estas condiciones de control, Moreno ha enfrentado un escenario de negociación política en el parlamento que le resultaba novedoso.

Amorim Neto (2006) sostiene que los presidentes pueden gobernar con decretos o leyes. Los presidentes siguen el primer camino, el de los decretos en la medida que no tienen contingente legislativo. Un presidente que gobierna designa ministros técnicos e independientes y/o personas de su círculo de confianza. Todos estos elementos de la teoría aplican para el caso del presidente Moreno. Como señalamos, sus ministros independientes y el apoyo en el congreso tiene que negociarlo ley por ley. Esta realidad también explica por qué el presidente decidió que la implementación del acuerdo con el FMI no se discutiera y se tramitara vía decreto, sin negociación con otros actores políticos, informando a través de la prensa su decisión.

En este escenario, el 2019 fue un año de particular interés para el gobierno ya que correspondía, por mandato constitucional, la reestructuración de la Asamblea Nacional. La tarea del ejecutivo entonces era doble, por una parte, debía asegurar la mayor influencia posible en el parlamento para sostener su gestión $y$, por otra parte, necesitaba repartir algunos de esos lugares de influencia, originalmente entregados a sus ex compañeros de partido, ahora correístas, de tal modo que pudiera contar con los apoyos necesarios provenientes de otras bancadas en el parlamento.

La competencia por alcanzar los puestos de mayor influencia en el parlamento comenzó meses antes de la reestructuración de mayo de 2019. En febrero, el ala correísta del parlamento presentó una denuncia en contra de la presidenta de la Asamblea, Elizabeth Cabezas, por presunto tráfico de influencias, al filtrarse un audio en donde se escuchaba a la titular de la legislatura discutir con la Ministra de Gobierno la necesidad de conseguir los apoyos necesarios para evitar una investigación al presidente Moreno, a causa de otra información filtrada que lo vincularía con la tenencia de activos en paraísos fiscales, lo cual está prohibido para los funcionarios públicos en Ecuador. Esta acusación llevaría a la conformación de una comisión para investigar las acciones de la presidenta de la Asamblea y, si bien no fue sancionada, el proceso tomó dos meses y desgastó a la bancada de Alianza País que, al momento de la votación en el pleno, se fraccionaría porque el anterior presidente de la legislatura, José Serrano, perteneciente a la agrupación política y destituido de la presidencia por una situación similar, ${ }^{13}$ reuniría apoyos para la sanción de su compañera de bancada.

12 El hexágono fue "un espacio de análisis político y jurídico en donde se discuten los proyectos de ley, el cual está conformado por actores ministeriales, de la Asamblea Nacional y la Secretaría Jurídica de la Presidencia. Según el tipo de ley acuden algunos representantes de ministerios" (Ramírez 2017: 22)

13 Se lo sancionó a causa de un audio filtrado en donde se lo escuchaba discutir con el ex Contralor General de la República, para ese entonces prófugo de la justicia (El Comercio 2018). 
Tras este episodio en la Asamblea, Cabezas no pudo presentarse a la reelección como presidenta del legislativo y Alianza País tuvo que buscar un candidato de consenso interno y luego negociar con dos agrupaciones de asambleístas independientes y con el partido de derecha, originalmente de oposición, CREO (Vélez 2019c). Esta coalición permitió la elección de César Litardo de AP como presidente del parlamento, a asambleístas de CREO e independientes como primer y segundo vicepresidente, y a cuatro vocales del Consejo de Administración Legislativa (CAL), dos de Alianza País, uno de CREO y uno del Partido Social Cristiano (PSC). De igual modo se reconfiguraron las trece comisiones permanentes de la Asamblea y en ningún caso se permitió que asambleístas correístas accedieran a las presidencias o vicepresidencias de estas.

Este acuerdo, sin embargo, presentó sus dificultades desde el primer momento cuando tres de las comisiones permanentes no se lograron conformar por disputas internas entre asambleístas de AP y de CREO. De hecho, estas comisiones tendrían que ser intervenidas por el Pleno de la Asamblea Nacional que nombraría a sus autoridades un poco más de un mes después de su instalación. Pese a esta intervención, dos de esas comisiones permanecerían bloqueadas y sin trabajar seis y siete meses (hasta que se permitió la selección de otras autoridades y cuando dos asambleístas de oposición finalmente dieron el quórum necesario para trabajar). Estos hechos muestran la fragilidad del acuerdo político con el que trabajaría el gobierno durante el 2019, gracias al que ha podido llevar adelante su agenda legislativa, pese a que, dentro de la propia bancada de Alianza País, como en la de CREO y demás aliados, ha habido votos en contra del gobierno. ${ }^{14}$

Otro tema que ha ocupado a la Asamblea Nacional durante esta legislatura y, particularmente, durante el año 2019, ha sido el trámite de juicios políticos. Desde el 2017 hasta final de 2018, ya varios juicios habían sido tramitados en la legislatura, entre ellos, los del ex Contralor General del Estado Carlos Polit; del ex Superintendente de Comunicación Carlos Ochoa; y del ex Fiscal General del Estado Carlos Baca Mancheno, terminaron en sendas censuras. Los juicios del exvicepresidente Jorge Glas; del presidente del Consejo de la Judicatura Gustavo Jalkh, y del ex Superintendente de Bancos, Cristian Cruz fueron suspendidos. El juicio contra el ex Ministro de Agricultura Rubén Flores fue archivado antes de llegar al Pleno de la Asamblea y el del ex Ministro de Economía Carlos de la Torre fue archivado por no haber contado con los votos necesarios para su censura. En total, ocho procesos se habían desarrollado en la Asamblea Nacional en poco menos de dos años. Durante el 2019, ocho procesos más de juicios políticos se han llevado a cabo en los que dos exfuncionarios fueron censurados, y cuatro fueron censurados y destituidos por la Asamblea Nacional, según se describe en la tabla 2.

14 Dada la política de alianzas de Moreno, entre los correístas, es común escuchar la acusación de que el presidente representa a la vieja partidocracia. Este concepto es usado de manera despectiva, ya para el correísmo "la partidocracia se entiende como la hegemonía absoluta de partidos tradicionales, que Rafael Correa consideró responsables de las crisis políticas en el pasado" (Jaramillo 2018:70). 
Tabla 2. Trámite de Juicios Políticos durante el 2019

\begin{tabular}{|c|c|c|}
\hline Nombre & Cargo & Estado del proceso \\
\hline Diego García & Ex Procurador entre 2007 y 2017 & Censurado el 2019.01.17 \\
\hline $\begin{array}{l}\text { María Fernanda } \\
\text { Espinosa }\end{array}$ & $\begin{array}{l}\text { Ex Ministra de Relaciones } \\
\text { Exteriores entre } 2017 \text { y } 2018\end{array}$ & $\begin{array}{l}\text { No hubo votos para la censura en } \\
\text { sesión del 2019.05.06 }\end{array}$ \\
\hline Verónica Espinosa & Ministra de Salud entre 2017 y 2019 & $\begin{array}{l}\text { Censurada en reconsideración de la } \\
\text { votación el 2019.08.14 }\end{array}$ \\
\hline José Tuárez & $\begin{array}{l}\text { Presidente del Consejo de } \\
\text { Participación Ciudadana y Control } \\
\text { Social (CPCCS) }\end{array}$ & Censurado y destituido el 2019.08.14 \\
\hline Walter Gómez & Vocal del CPCCS & Censurado y destituido el 2019.08.14 \\
\hline Victoria Desintonio & Vocal del CPCCS & Censurada y destituida el 2019.08.14 \\
\hline Rosa Chalá & Vocal del CPCCS & Censurada y destituida el 2019.08.14 \\
\hline Raúl Pérez Torres & $\begin{array}{l}\text { Ex Ministro de Cultura entre } 2017 \\
\text { y } 2019\end{array}$ & $\begin{array}{l}\text { No hubo votos para la censura e } \\
\text { sesión del 2020.01.15 }\end{array}$ \\
\hline
\end{tabular}

Fuente: Asamblea Nacional de Ecuador. Votaciones del Pleno. https://www.asambleanacional.gob.ec/es/votaciones-del-pleno

Asimismo, se han iniciado cinco procesos que no han llegado a juicio político, en una ocasión fue en contra de los miembros del Consejo de la Judicatura anterior, otra en contra del Ministro de Finanzas, Richard Martínez, y en dos ocasiones en contra de la Ministra de Gobierno María Paula Romo. Sin embargo, la iniciativa de juicio político que llevó a CREO a anunciar públicamente la ruptura del acuerdo político con AP fue aquella en contra de la presidenta del Consejo Nacional Electoral (CNE), Diana Atamaint, promovida por el bloque de CREO. En un año previo a las elecciones generales de 2021, su remoción hubiese implicado una reorganización dentro del órgano encargado de organizar el referido proceso electoral; sin embargo, en el momento de la votación el 1 de febrero de 2020, en la Comisión de Fiscalización de la Asamblea Nacional, instancia previa al inicio del juicio político en el Pleno de la Asamblea, solo se obtuvieron seis de los siete votos necesarios para llevar a juicio político a la funcionaria. El voto faltante fue responsabilidad de dos asambleístas de AP que en un caso no se presentó a la votación y en el otro envío a su suplente quien votó en contra (El Comercio 2020a).

Esta serie de iniciativas de juicio político, sumada a un importante número de llamados a comparecencia en las Comisiones de la Asamblea Nacional a funcionarios del ejecutivo, da cuenta de un equilibrio débil en el que, por una parte, el legislativo le da señales al ejecutivo que lo obliguen a negociar y no gobernar mayoritariamente vía decreto. Por otra parte, el ejecutivo al contar con escazas herramientas de negociación, ha utilizado (principalmente en 2018) la posibilidad de investigación y potencial sanción sobre los asambleístas que han incurrido en la referida práctica de los diezmos ${ }^{15}$. De este modo, con amenazas 
de lado y lado, el 2019 mantuvo, no sin dificultad, un equilibrio que le permitió a Moreno aprobar iniciativas legislativas que, sobre todo en el ámbito económico, resultaban apremiantes (la tabla 3 da cuenta de los proyectos presentados por el gobierno durante el 2019)

Tabla 3. Proyectos presentados por Moreno 2019

\begin{tabular}{|c|c|c|}
\hline $\begin{array}{l}\text { Fecha de } \\
\text { Presentación }\end{array}$ & Proyecto & Estado \\
\hline $21 / 11 / 2019$ & $\begin{array}{l}\text { Proyecto de Ley Orgánica de Simplicidad y Progresividad Tributa- } \\
\text { ria (urgente en materia económica) }\end{array}$ & Publicado \\
\hline $18 / 10 / 2019$ & $\begin{array}{l}\text { Proyecto de Ley Orgánica para la Transparencia Fiscal, Optimi- } \\
\text { zación del Gasto Tributario, Fomento a la Creación de Empleo, } \\
\text { Afianzamiento de los Sistemas Monetario y Financiero, y Manejo } \\
\text { Responsable de las Finanzas Públicas (urgente en materia econó- } \\
\text { mica) }\end{array}$ & $\begin{array}{l}\text { Archivado } \\
\text { (rechazado) }\end{array}$ \\
\hline $19 / 09 / 2019$ & Proyecto de Ley Orgánica de Protección de Datos Personales & En trámite \\
\hline $02 / 09 / 2019$ & $\begin{array}{l}\text { Proyecto de Ley Orgánica Reformatoria al Código Orgánico de la } \\
\text { Función Judicial }\end{array}$ & En trámite \\
\hline $20 / 08 / 2019$ & $\begin{array}{l}\text { Proyecto de Ley Orgánica de Personal y Disciplina de Fuerzas Ar- } \\
\text { madas }\end{array}$ & En trámite \\
\hline $16 / 08 / 2019$ & Proyecto de Ley Orgánica de Pesca y Acuicultura & Publicado \\
\hline $30 / 07 / 2019$ & $\begin{array}{l}\text { Proyecto de Ley Orgánica Reformatoria a la Ley Orgánica de Mo- } \\
\text { vilidad Humana }\end{array}$ & En trámite \\
\hline $18 / 06 / 2019$ & $\begin{array}{l}\text { Proyecto de Ley Orgánica Reformatoria al Código Orgánico Inte- } \\
\text { gral Penal }\end{array}$ & En trámite \\
\hline $31 / 05 / 2019$ & $\begin{array}{l}\text { Proyecto de Ley Derogatoria al Impuesto Ambiental a la Contami- } \\
\text { nación Vehicular (Impuesto Verde) }\end{array}$ & Publicado \\
\hline $18 / 01 / 2019$ & $\begin{array}{l}\text { Proyecto de Ley Orgánica Reformatoria al Artículo } 5 \text { de la Ley Or- } \\
\text { gánica de Comunicación }\end{array}$ & En trámite \\
\hline
\end{tabular}

Fuente: Asamblea Nacional de Ecuador. Consultas de propuestas y proyectos de ley. https:/ / leyes.asambleanacional.gob.ec/

Llama la atención que desde el inicio de su período en 2017 hasta diciembre del año 2019 el ejecutivo presentó 20 proyectos de ley de los cuales 11 llegaron a ser publicados y uno fue expresamente rechazado. Estas cifras contrastan con el gobierno de Rafael Correa que en periodos similares (es decir 31 meses de gobierno) tuvo un desempeño mucho mejor. Correa entre 2009 y 2011 presentó 53 proyectos de los cuales 37 fueron publicados, y entre 2013 y 2015, presentó 29 proyectos y 25 fueron publicados.

Durante el gobierno de Correa, ningún proyecto presentado por el ejecutivo fue expresamente rechazado por la Asamblea Nacional, ${ }^{16}$ toda vez que después 
de la constituyente Correa tenía una mayoría abrumadora en el legislativo. Como el ejecutivo contaba con muchos recursos, por el alto precio del petróleo, Correa utilizaba un sistema de incentivos, sobre todo durante el período 2013-2017, en cual premiaba a sus congresistas, permitiéndoles presentar en la asamblea como suyos proyectos diseñados en el ejecutivo. Esta práctica servía era un premio pues permitía a los legisladores reclamar crédito en sus distritos electorales por la presentación de una ley que los beneficiaria, un claro ejemplo de ello es la Ley Orgánica de Movilidad Humana, preparada por el Ministerio de Relaciones Exteriores y Movilidad Humana, pero presentada a la Asamblea Nacional por los asambleístas electos por los distritos de los ecuatorianos residentes en el exterior es un claro ejemplo de este mecanismo empleado por el ejecutivo (Ramírez 2017).

El gobierno de Moreno en 2019, en este contexto, cuenta con un equipo cercano sin la capacidad política necesaria para asegurar apoyos estables en el parlamento. Muestra de ello es que su "Proyecto de Ley Orgánica para la Transparencia Fiscal, Optimización del Gasto Tributario, Fomento a la Creación de Empleo, Afianzamiento de los Sistemas Monetario y Financiero, y Manejo Responsable de las Finanzas Públicas" fue la primera iniciativa presentada por el ejecutivo archivada desde 2009. ${ }^{17}$ Además, este equipo con perfil tecnócrata, tampoco aseguró los apoyos necesarios de la sociedad civil a la gestión del gobierno, que podría balancear su debilidad parlamentaria, lo que, en una coyuntura económica ajustada como la vivida en 2019, llevaría a una agudización de la crisis económica, política y social del Ecuador que alcanzó su clímax en la protesta de octubre de ese año.

\section{LA PROTESTA DEL 2019}

Las protestas de octubre se desarrollaron como respuesta a una acción gubernamental. El anuncio del decreto $\mathrm{N}^{\circ} 833$ generó la oportunidad para que grupos organizados (sindicatos y organizaciones indígenas) junto a ciudadanos afectados por la medida (y que no forman parte de los grupos organizados) se movilicen con técnicas disruptivas y no convencionales (marchas y protestas), para presionar a la estructura estatal y así para obtener algún beneficio (este caso es la eliminación del subsidio). Los movimientos sociales pueden incidir en diversas etapas del proceso de las políticas públicas, los investigadores de estas temáticas pueden contribuir a entender los efectos del movimiento (si la política fue detenida o no) o cómo se incorporaron en la agenda pública los elementos del movimiento social, es decir, comprender la capacidad de la agen-

17 En la práctica política parlamentaria de Ecuador, desde 2008, no ha sido común que se archiven proyectos de ley presentados por el ejecutivo. Esto no quiere decir que todos han sido aprobados, sino que aquellos que no alcanzan el apoyo suficiente para su aprobación quedan en un limbo jurídico en el que no son archivados, ni aprobados. 
da, los efectos en el diseño de una política y sus circuitos de retroalimentación (Silva 2015:30).

Para entender cómo una protesta logra frenar una política pública, es importante considerar el origen del movimiento, su desarrollo, estrategia de los actores y sus impactos. Estos puntos pueden ser considerado en futuras investigaciones para comprender en profundidad cómo fue el proceso en el cual un movimiento social tiene incidencia para frenar la política fiscal (o cualquier política) del caso ecuatoriano (recomendamos los trabajos de Barragán et al. 2020; Ramírez, 2020, que analizan las protestas) no obstante, con estos elementos como limitantes, en las siguientes páginas repasamos las etapas de la protesta de octubre de 2019, las estrategias de los principales actores políticos y el impacto en el gobierno.

El decreto de eliminación del subsidio a los hidrocarburos generó en Ecuador una de las crisis más importantes de los últimos años (Barragán et al. 2020; Ramírez 2019, 2020). La escalada de la protesta fue rápida. A dos días del anuncio, la capital quedó sin transporte por el paro de los operadores de taxis, buses y camiones que exigían la eliminación del decreto. Al cuarto día, la protesta escaló con la llegada de las comunidades indígenas para bloquear la capital, exigir la mantención del subsidio y la salida del presidente. Estas protestas, que revivieron los fantasmas de las caídas presidenciales, inestabilidad política y crisis institucional, paralizaron al país y como veremos a continuación, permitieron el despliegue de diversas estrategias acrecentando los problemas del gobierno y los niveles de polarización en la sociedad.

\section{El contexto general}

La situación económica de Ecuador ha sido unos de los principales problemas que ha debido enfrentar el gobierno de Moreno. La caída de los precios del petróleo desde el 2014 dejó en evidencia que el periodo de bonanza económica no se tradujo en inversión de largo plazo. No hubo una política fiscal que permitiese ahorrar, para mantener los niveles de gasto e inversión que se desarrollan durante el boom petrolero, producto de la centralización de la economía en el Estado como proyecto post neoliberal (Sánchez y Polga-Hecimovich 2019). El gobierno acrecentó el gasto público y, para mantenerlo, su nivel de endeudamiento (gráfico 1). Además, se hizo evidente que el desarrollo del sector privado fue muy bajo y se mantuvo como poco competitivo (Barragán et al. 2020).

Este panorama económico se completa al observar algunas cifras particularmente malas del 2019. Por ejemplo, la tasa de crecimiento porcentual anual del PIB, la cual según el Banco Mundial fue la más baja del gobierno. Tal como se observa en el gráfico 2 esta es una tendencia que, si bien tuvo una recuperación después de la cifra más negativa, hasta ahora, en el 2016 (último año de Rafel Correa), comienza a descender nuevamente en el gobierno de Moreno. Las proyecciones para el 2020 auguran un año complicado para el gobierno, ya que la 
Gráfico 1. Deuda pública de Ecuador (\% del GDP)

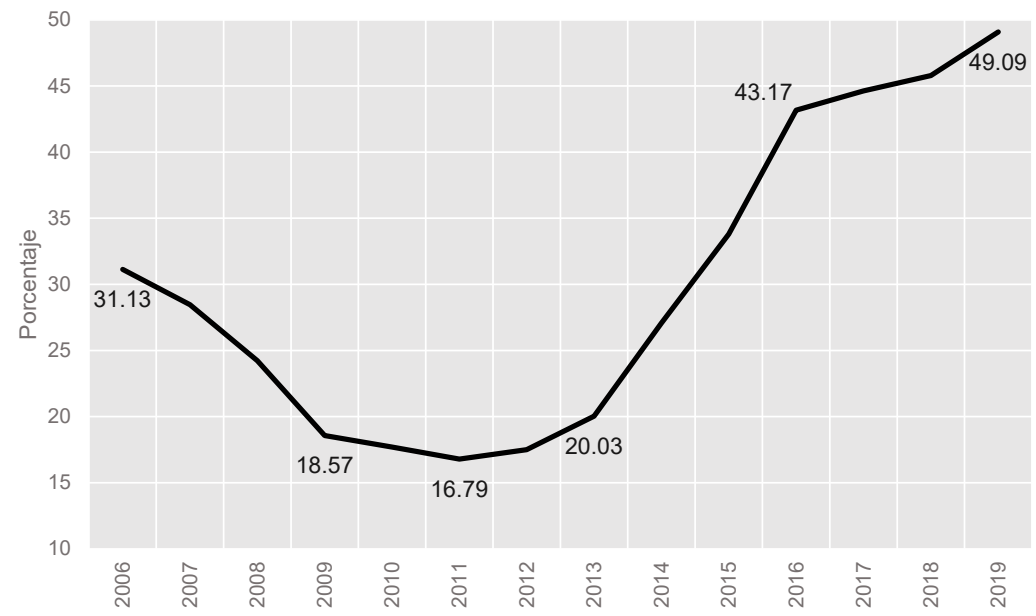

Elaboración propia a partir de Fondo Monetario Internacional (2019b)

variación del PIB sería peor incluso que la del año de la crisis de 1999 (ese año la variación del PIB fue de -4.7).

Gráfico 2. Tasa de crecimiento porcentual anual del PIB

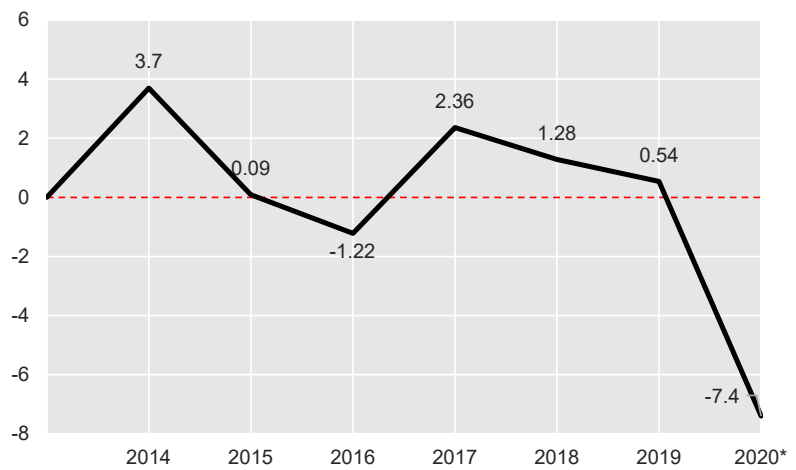

Fuente: Banco Mundial (2020). Precios de mercado sobre la base de dólares de EE. UU constantes de 2010. (*) Proyección.

Para complementar un panorama más complejo, el gobierno ha sido incapaz de mejorar los indicadores de pobreza del país. Según las estadísticas del Instituto 
Nacional de Estadística y Censos (INEC) para el 2019 un cuarto de la población ecuatoriana se encuentra bajo la línea de pobreza por ingresos y el 38.1\% de los ecuatorianos vive en pobreza multidimensional, es decir, que aun cuando alcancen el ingreso mínimo su acceso a educación; trabajo y seguridad social; salud, agua y alimentación o vivienda se encuentra limitado. Ambos indicadores presentaron el 2019 su peor desempeño desde 2013.

\section{Gráfico 3. Pobreza en Ecuador}

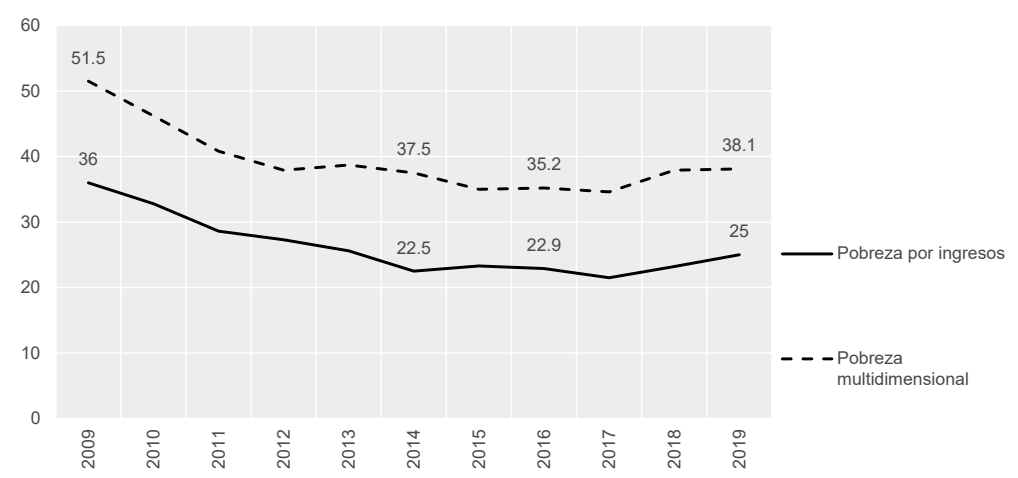

Fuente: Elaboración propia con datos de Instituto Nacional de Estadística y Censos (2019).

En un escenario complejo para las finanzas públicas, sin crecimiento, con pobreza en aumento y un gasto público alto, la eliminación del subsidio a los hidrocarburos parecía una medida razonable, que permitía ahorros importantes al estado. Asimismo, esta eliminación podría contar con amplio consenso político, porque incluso Rafael Correa, siendo presidente, en agosto de 2013 señaló que ese tipo de subsidios favorecía solo a los más ricos (El Telégrafo 2013).

No obstante, los anuncios de Moreno de liberalización de precios del diésel y la gasolina; eliminación y reducción de aranceles para maquinarias agrícolas e industriales, la entrega de bonos de 15 dólares mensuales a las familias; eliminación de aranceles a la importación de computadores, celulares y tabletas; y rebajas en la remuneración de los funcionarios públicos (El Comercio 2019a), desató una movilización social sin precedentes en la última década en Ecuador.

Lo anterior, al no contar con el respaldo de grupos organizados con capacidad de convocatoria, generó un problema para el presidente. Estos grupos, principalmente indígenas, considerarían que la eliminación del subsidio los perjudicaba, debido a que una de las medidas era subir los precios del combustible. Al parecer tampoco se ponderó el impacto en la ciudadanía no organizada que vio en un par de días que subiría el precio del transporte público de 25 a 35 centavos de dólar por pasaje. Ante esto, la falta de previsión de los impactos es otro ejemplo de la falta de diálogo que tiene el gobierno. No conversó con 
organizaciones de usuarios, tampoco con las comunidades indígenas, ni con los transportistas, actores que serían el grupo focal afectado directamente por el decreto Sumando a esto, el presidente no buscó consenso político para que sus medidas fuesen respaldadas. Esta falta de previsión sobre los efectos sociales y políticos de sus medidas, da cuenta de la inexistencia de diálogo y de estrategia para enfrentar los problemas del país.

Además de esto, el gobierno parece no conocer la historia reciente del país. En enero de 1997 Abdalá Bucaram anunció una serie de reformas que incluían alzas de impuestos a los combustibles y eliminación de subsidios a los servicios de gas, teléfonos y electricidad. Estas medidas fueron las que gatillaron la molestia final contra el presidente que en febrero del mismo año debió dejar el cargo. En otras palabras, el intento por eliminar el subsidio al gas le costó la presidencia a Abdalá Bucaram. Hoy, estuvo muy cerca de costarle la presidencia a Moreno. ${ }^{18}$

\section{El estallido de octubre}

Si consideremos la falta de conducción política del gobierno y la mala situación de la economía, la propuesta económica del presidente, que implicaban la eliminación de los subsidios a los combustibles, abrió la ventana de oportunidad para que diversos actores políticos y sociales, organizados y no organizados, manifestaran su oposición al gobierno y lo presionaran para cambiar de posición. También fue la oportunidad para que parte de la oposición más radical, como el correísmo, pidiera la renuncia del presidente y que se llamase a nuevas elecciones (GK City 2019). El gobierno y la institucionalidad política debieron enfrentar duros embates de diversos sectores políticos y sociales, que hicieron temer una nueva caída presidencial.

Los primeros actores organizados que se movilizaron fueron los transportistas. Esta protesta estaba destinada a ser breve, ya que muy pocos actores políticos hubiesen apoyado las demandas que implicaban ceder ante un grupo de poder económico muy desprestigiado. En este contexto, el gobierno utilizó estrategias efectivas para disminuir la credibilidad de este gremio. Al iniciar la paralización, el aparto de comunicación gubernamental, para evitar la solidaridad de otros sectores, hizo públicas las deudas de los dirigentes con el Estado, sus evasiones de impuestos y su patrimonio sin justificar (Teleamazonas 2019). El gobierno sabía que los transportistas iban a responder a las medidas de ajuste y estaban listos para desacreditarlos y dividirlos. De hecho, bajaron su paro a los pocos días.

18 Sobre la caída de Bucaram recomendamos Pachano (1997), sobre los problemas de la democracia ecuatoriana desde la instauración de la democracia hasta la llegada de Correa ver Basabe-Serrano et al. (2010). 
Sin embargo, otro actor inesperado que se organizó y manifestó fue el movimiento indígena. La Confederación de Nacionalidades Indígenas del Ecuador (CONAIE) logró en pocos días movilizar, desde las zonas rurales del país, a las comunidades para marchar a la capital. La CONAIE parecía así recuperar la capacidad de movilización que tenía en los años ochenta y noventa. La organización bloqueó la capital y logró movilizar a diversos sectores de la población que se consideraban afectados por el decreto. La respuesta estatal fue errática. A nivel comunicacional el gobierno acusó a los manifestantes de ser correístas, de recibir financiamiento ilegal del narcotráfico o de que Maduro instigó las protestas (BBC News Mundo 2019). Este error del gobierno de descalificar la protesta aumentó el malestar de los manifestantes y provocó que cada concentración fuese mayor a la anterior y que el correísmo aprovechase esta ventana de oportunidad para entrar en el juego político pidiendo la renuncia del presidente.

El presidente, en ese momento, decretó estado de excepción constitucional y trasladó la sede de gobierno a Guayaquil. ${ }^{19}$ Esta última acción evitó en gran medida, la caída del presidente ya que vació de poder y de simbolismo a la capital que en otras crisis políticas fue determinante en las salidas de los mandatarios. Rodrigo Paz Delgado, ex alcalde de la ciudad resumió el peso simbólico de la capital cuando afirmó que "todo gobierno debe comprender lo que se comenta: que Guayaquil pone presidentes, pero Quito los bota" (La Hora 2006). Adicionalmente, la instalación del gobierno en la ciudad costeña forzó al Partido Social Cristiano, originalmente en contra del decreto, a alinearse con el gobierno para evitar un enfrentamiento abierto. Con esto el gobierno acalló una de las tantas voces críticas.

Entonces, la protesta en la capital se concentró alrededor del parlamento, edificio convertido en una trinchera de la policía y que se ubicó a pocos metros de la Casa de la Cultura Ecuatoriana, lugar que fue el epicentro de la concentración indígena. En términos del enfrentamiento en las calles de las fuerzas policiales, de las Fuerzas Armadas y de los manifestantes, distintas realidades se vivieron simultáneamente. Por una parte, grupos pertenecientes al movimiento indígena, realizaban marchas con un grado de violencia relativamente bajo, sin embargo, al encontrarse con los bloqueos de las fuerzas policiales, un grupo de choque conformado por organizaciones con distintos orígenes desplegaban tácticas de avance y resistencia que daban cuenta de una preparación previa (El Universo 2019a) y, en algunos casos, mostraban extrema violencia (El Comercio 2019b).

Por otra parte, la respuesta de las fuerzas policiales también se exacerbó. Muestra de esto fue el lanzamiento de bombas lacrimógenas a los campus de la Pontificia Universidad Católica del Ecuador y de la Universidad Politécnica Salesiana, que habían sido designados como zona humanitaria y en donde se 
albergaban heridos y menores de edad de las comunidades indígenas que se estaban movilizando a Quito para protestar (Díaz y Rosero 2019). El punto más álgido de estas represalias llegó la noche del 12 de octubre, un día antes de la mesa de negociación acordada entre el gobierno y el movimiento indígena, cuando la policía rodeó los campus de las referidas universidades, y el personal de salud formó un cordón humano para proteger la zona hasta que las fuerzas policiales se retiraran (Gamavisión 2019b).

Distinto rol jugaron las Fuerzas Armadas, en donde se puede distinguir, por una parte, el tono de las amenazantes declaraciones del Ministro de Defensa, el ex militar Oswaldo Jarrín, quien afirmó que la protesta eran acciones terroristas, por lo tanto, justificó el uso de la fuerza (Gamavisión 2019a). Por otra parte, está la disuasión moderada que los uniformados mostraron cuando, en los casos de confrontación con los manifestantes, depusieron el uso de la violencia e incluso cedieron para evitar la escalada del conflicto. Muestra de ello es que en varios casos fueron "capturados" por los manifestantes sin resistencia para luego ser liberados, y que incluso abandonaron material bélico para no utilizarlo en contra de los manifestantes (El Comercio 2019c, 2019d). La intencionalidad de este bajo nivel de represión por parte de las Fuerzas Armadas se hizo evidente en el discurso de despedida del Comandante del Ejército, quien fue destituido del cargo tras las manifestaciones de octubre (El Comercio 2019e).

Tras once días de manifestaciones y producto de negociaciones que fueron mediadas por el Coordinador Residente de las Naciones Unidas en Ecuador y miembros de la Iglesia Católica, el presidente Moreno y los líderes del movimiento indígena acordaron la instalación de una mesa de negociación. Este acuerdo dejó entrever también las fisuras de los diferentes grupos que protestaban, en general, y del movimiento indígena en particular. Por una parte, a pocas horas del inicio de las negociaciones la violencia en la capital recrudeció con ataques e intentos de incendio a medios de comunicación por parte de los grupos de choque no asociados al movimiento indígena que habían participado en las manifestaciones; y, por otra parte, la dirigencia de la CONAIE emitió comunicaciones contradictorias cuando accedió a las negociaciones, luego dio marcha atrás desmintiendo su carta original, para finalmente aceptar el proceso de diálogo. Esto permite inferir que, si bien el movimiento indígena logró movilizar a sus bases, es necesario matizar la homogeneidad de los intereses de los diferentes grupos que están contenidos dentro de este potente sector social y las intensas negociaciones internas que existieron para finalmente sentarse frente a frente con el gobierno.

Ya en la negociación, la cual fue televisada, pero que tuvo una transmisión interrumpida durante varias horas, tanto los delegados del movimiento indígena y del gobierno, acordaron la derogación inmediata del Decreto Ejecutivo que diera origen a la crisis política. Otro logro del movimiento fue que se instalaría una mesa de negociación posterior para avanzar en una propuesta para la mejor gestión de los subsidios (Primicias 2019). 
El movimiento indígena logró reorganizar sus bases y mostrar una capacidad de movilización que no se había visto desde hace muchos años y volver a ser uno de los actores sociales con más fuerza en el país, lo cual conllevó a que lograran la derogación del Decreto Ejecutivo y el mantenimiento de los subsidios a los combustibles. Sin embargo, el desenlace de las protestas no dejó ganadores ni perdedores absolutos, sino que también se observó el fraccionamiento interno del movimiento, lo que evitó que pudiesen ejercer presión durante más tiempo al gobierno, en cuyo caso, incluso la permanencia de Moreno en la presidencia hubiese estado en entredicho.

El fin del conflicto dejo el saldo humano fue de 8 fallecidos y 1.340 heridos, según cifras de la Institución Nacional de Derechos Humanos del Ecuador llamada Defensoría del Pueblo (El Universo 2019b). También logró, contra varios pronósticos, la mantención de Moreno en el gobierno, sin embargo, para ello tuvo que renunciar a su iniciativa de política pública lo que complicó aún más sus perspectivas económicas. En otras palabras, para lograr cierta estabilidad del gobierno sacrificó las reformas, logrando un precario equilibrio: permanecer en el gobierno a cambio de no poder desarrollar los planes económicos del presidente.

Con todo esto, una pregunta que aún queda por responder es ¿por qué no cayó Moreno? Ecuador es un país, donde movimientos sociales han tenido la capacidad de sacar presidentes de sus cargos e incluso se ha llegado a hipotetizar que constituyen una institución informal en Ecuador (Polga Hecimovich 2010). Es decir, los presidentes ecuatorianos siempre están en peligro de caer, por eso es necesario explicar en futura investigación académica, ¿por qué, con todo en contra, Moreno se mantuvo en el poder después de octubre? Se trata de un gobierno con oposiciones cruzadas (tiene adversarios a la derecha y a la izquierda), no posee una plataforma política estable (su gabinete carece de experiencia política), no tiene bancada estable ni mayoría en el congreso. Su permanencia en el poder es llamativa ya que, durante el 2019, aún existía la posibilidad de llamar a elecciones de forma anticipada, fenómeno conocido como muerte cruzada. La hipótesis que quizás se debería buscar comprobar es que es un presidente que se sostiene por una serie de equilibrios precarios que generan un statu quo, en que el costo de su salida es más alto que mantenerlo, ya que su salida podría implicar la vuelta de Correa al poder, aunque sea por interpósita persona.

Esto último se ve reforzado por la retórica del gobierno que durante todo el proceso el gobierno acusó que parte de los manifestantes no buscaban la eliminación del subsidio sino la salida del presidente (Valencia 2019). De hecho, en varias oportunidades, el ejecutivo acusó de que se trataba de un intento de golpe de estado, organizado por los líderes del correísmo. Por eso una vez que el conflicto se solucionó, inició procesos judiciales contra los principales líderes del Movimiento Revolución Ciudadana, entre ellos Paola Pabón perfecta de Pichicha (provincia donde está la capital) que estuvo en prisión preventiva entre el 15 de octubre y 26 de diciembre (El Comercio 2019f; El Universo 2019c; El Universo 2019d). 


\section{CAMBIOS INSTITUCIONALES, RESULTADOS ELECTORALES $Y$ NUEVA REFORMA POLÍTICA.}

Freidenberg y Dosek (2016), realizan una clasificación de 18 países latinoamericanos en función del número de reformas políticas que han experimentado entre el 2015 y año del retorno a la democracia. En esta clasificación Ecuador se ubica en la primera posición por el número de reformas que ha realizado en su último periodo democrático. Esa tendencia se mantiene y en el año 2019, Ecuador culminó con un nuevo proceso de reforma política que habría comenzado en el 2018 con el referéndum (de acuerdo con la definición de Altman 2019) que, por una parte, retrocedió en todas las reformas constitucionales que la Asamblea Nacional impulsó en 2015 (siendo probablemente la más polémica, la de la reelección indefinida), y por otra parte, modificaba el Consejo de Participación Ciudadana y Control Social (CPCCS), la principal institución del quinto poder del estado ecuatoriano (además del Legislativo, Ejecutivo, Judicial y Electoral), la Función de Transparencia y Control Social.

El Consejo de Participación Ciudadana y Control Social temporal (CPCCS-T), que emanó de la consulta popular, tenía como labor reestructurar la Función de Transparencia y Control Social a través de la evaluación y, de ser el caso, remoción y reemplazo de las autoridades que se agrupan en ella. Su rol, sin embargo, no se detenía ahí. Dado que el CPCCS participa en la selección y nombramiento de autoridades de otras funciones y órganos, el CPCCS-T podía revisar todos los nombramientos en los que su antecesor había participado. En la tabla 4 se resumen los cargos que entraron a evaluación.

Tabla 4 Autoridades designadas o electas por el CPCCS

\begin{tabular}{ll}
\hline Organismo & Autoridad \\
\hline Contraloría General del Estado & Contralor \\
Defensoría del Pueblo & Defensor del Pueblo \\
Defensoría Pública & Defensor Público \\
Fiscalía General del Estado & Fiscal General \\
Consejo Nacional Electoral & Cinco vocales titulares y sus suplentes \\
Tribunal Contencioso Electoral & Cinco vocales titulares y sus suplentes \\
Delegados ciudadanos al Banco del Instituto Ecua- & Un delegado por los afiliados y uno por \\
toriano de Seguridad Social & los jubilados \\
Procuraduría General del Estado & Procurador General \\
Superintendencia de Compañías & Superintendente \\
Superintendencia de Bancos & Superintendente \\
Superintendencia de Economía Popular y Solidaria & Superintendente \\
Superintendencia de Control del Mercado & Superintendente \\
Superintendencia de Comunicación & Superintendente \\
\hline
\end{tabular}




\begin{tabular}{ll}
\hline Organismo & Autoridad \\
\hline $\begin{array}{l}\text { Superintendencia de Ordenamiento Territorial, Uso } \\
\text { y Gestión del Suelo }\end{array}$ & Superintendente \\
Consejo de la Judicatura & Cinco vocales titulares y sus suplentes \\
Corte Constitucional & Nueve jueces \\
\hline
\end{tabular}

Elaboración propia. Fuente: Constitución de la República del Ecuador 2008. *Extinta el 31 de julio de 2019 con la reforma a la Ley Orgánica de Comunicación (García 2019)

El caso más importante por el peso que tiene en la arquitectura institucional ecuatoriana como organismo de última instancia constitucional y su rol como protectora de derechos y árbitro de la política (Sotomayor 2019) es, probablemente, la Corte Constitucional. En agosto de 2018, el CPCCS-T cesó en sus funciones a los nueve jueces constitucionales e inició el proceso de selección de sus reemplazos. En febrero de 2019, asumieron los nuevos jueces generando una configuración que, en términos generales, reúne a juristas con amplia trayectoria profesional y que representan diversas posturas en el espacio ideológico.

En las elecciones de marzo de 2019 en la que se eligió a los miembros del CPCCS definitivo, las funciones del CPCCS-T llegaban a su fin y la nueva Corte Constitucional emitió un dictamen en el que se pronunció sobre las facultades especiales que este Consejo temporal había ejercido, razón por la que su gestión no podría ser objeto de revisión por parte del CPCCS electo para desempeñarse de acuerdo con las facultades ordinarias que la Constitución prevé para dicho organismo.

En junio de 2019, el CPCCS fue posesionado y su presidente José Tuárez, poco después, anunciaría el inicio de una revisión a lo actuado por el CPCCS-T en contra de lo expresamente dictaminado por la Corte Constitucional. Este hecho daría paso para que el parlamento lo enjuicie políticamente y lo destituya junto con tres vocales adicionales con los que Tuárez formaba mayoría en el CPCCS. Al mismo tiempo, por vías distintas, la Asamblea Nacional y un colectivo ciudadano recibirían el aval de la Corte Constitucional para iniciar un proceso de reforma constitucional que elimine o limite las funciones de Consejo de Participación Ciudadana y Control Social.

En el mismo proceso electoral se eligieron las autoridades locales correspondientes a 23 provincias y 221 municipios. Estas elecciones son importantes para la realidad política del país, ya que hay una gran variación entre los territorios dejando en evidencia "la existencia de diferencias entre las características del sistema de partidos a nivel nacional y a nivel provincial en lo que concierne a las elecciones nacionales" (Dandoy 2019: 136). Del mismo modo, estas elecciones provinciales cumplen la función de ser elecciones de medio término de gobierno. Por ello, existe la preocupación de la clase política por dichos resultados, considerando que el 2021 corresponde el desarrollo de elecciones generales (presidente, vicepresidente y la totalidad de parlamentarios). 
Como se observa en la tabla 5, existe una gran variación entre los territorios, con muchos movimientos locales y partidos de alcance solo en los territorios. Alianza País, el partido por el que Moreno llegó a la presidencia, en esta elección, producto de la fractura con el ala correísta, obtuvo a penas 2 prefecturas de 23 y 28 de 221 alcaldías de las cuales solo 1 fue capital de provincia. A nivel de otros partidos la situación no es muy distinta, en las elecciones municipales solo 13 alcaldes fueron reelegidos (aunque no siempre representando al mismo partido político, lo que da cuenta del caudillismo en términos de Basabe-Serrano (2018)) y 25 alcaldías se mantuvieron en las manos del mismo partido (de 221 en juego), a partir de estos datos se infiere que hubo gran volatilidad del escenario electoral. En este contexto, es relevante la elección de Jorge Yunda con el 21,39\% de los votos como alcalde de Quito. La fragmentación de las preferencias electorales en la capital es llamativa pues en esa ciudad, al menos desde la década de los 90, todos los alcaldes habían sido electos con más del 40\% de la votación.

Tabla 5. Partidos, movimientos o alianzas políticas ganadoras por provincia en 2019

\begin{tabular}{|c|c|}
\hline Provincia & Partido/ Alianza ganadora \\
\hline Azuay & Movimiento de Unidad Plurinacional Pachakutik \\
\hline Bolívar & Partido Social Cristiano \\
\hline Cañar & Partido Social Cristiano \\
\hline Carchi & Izquierda Democrática \\
\hline Chimborazo & Movimiento Político Provincial Cambio \\
\hline Cotopaxi & $\begin{array}{l}\text { Movimiento Unidad Popular y Movimiento de Unidad Plurina- } \\
\text { cional Pachakutik }\end{array}$ \\
\hline El Oro & $\begin{array}{l}\text { Movimiento Centro Democrático; MDSI; Movimiento Sur; Movi- } \\
\text { miento Alianza País }\end{array}$ \\
\hline Esmeraldas & Partido Social Cristiano \\
\hline Guayas & Partido Social Cristiano y Movimiento Madera de Guerrero \\
\hline Imbabura & Alianza Todos por Imbabura \\
\hline Loja & Alianza Loja Progresa \\
\hline Los Ríos & Partido Social Cristiano \\
\hline Manabí & Movimiento F. Compromiso Social \\
\hline Morona Santiago & Movimiento de Unidad Plurinacional Pachakutik \\
\hline Napo & Movimiento de Unidad Plurinacional Pachakutik \\
\hline Orellana & Alianza Orellana \\
\hline Pastaza & $\begin{array}{l}\text { Alianza Movimiento Político Unidos por Pastaza - Partido Social } \\
\text { Cristiano }\end{array}$ \\
\hline Pichincha & Movimiento F. Compromiso Social \\
\hline Santa Elena & Alianza \\
\hline Sto Domingo de los Tsachilas & Unidad 20/100 \\
\hline Sucumbios & Movimiento Suma \\
\hline Tungurahua & Movimiento de Unidad Plurinacional Pachakutik \\
\hline Zamora Chinchipe & Alianza Juntos Podemos \\
\hline
\end{tabular}


De cara a las elecciones generales que se realizarán en 2021 y considerando los resultados electorales del 2019, los partidos políticos con representación en el parlamento han realizado una nueva reforma política que, en su parte fundamental, incrementan los controles sobre el financiamiento de campañas, ${ }^{20}$ establece una cuota progresiva que garantice hasta el 2025 que el 50\% de las listas pluripersonales de candidatos estén encabezadas por mujeres (desde 2009, la ley electoral ya preveía que las listas pluripersonales debían incluir igual número de hombres y mujeres, quienes deberían ser presentados de forma alternada pero no establecía ningún requisito sobre el género de la persona que encabeza la lista), establece que el binomio de candidatos a la presidencia y vicepresidencia de la república deberán estar conformados por un hombre y una mujer, modifica el método de asignación de escaños de D’Hondt a Webster incrementando la probabilidad de obtención de curules de organizaciones políticas con menor votación y establece la votación por listas cerradas.

Como hemos señalado, el 2019 confirma algunos elementos que serán importantes para el sistema político, de cara a las elecciones de 2021. Se cambia, nuevamente el sistema electoral. ${ }^{21}$ Pierde relevancia el CPSS y gana el poder legislativo, pero sin acuerdos políticos estables. ${ }^{22}$ La Corte Constitucional es una institución relegitimada y con amplias capacidades institucionales para el ejercicio de su rol de defensora de derechos y árbitro de la política.

\section{CONCLUSIONES}

El presente trabajo buscó entregar una mirada general sobre los principales elementos que son importantes para estudiar la política en Ecuador durante el 2019. Para comprender la crisis que vive el país, se analizaron los poderes ejecutivo y legislativo, dando énfasis a la figura del presidente, y el rol de este actor en la articulación dentro del sistema. Además, se realizó una narrativa respecto al desarrollo de las protestas de octubre y de los principales resultados de las transformaciones institucionales durante el año.

A partir del análisis de la literatura, constatamos que Ecuador no posee un hiper presidencialismo más allá de lo formal, aunque el jefe de gobierno tenga amplios poderes, no es cierto que existe una centralización en el ejecutivo. El sistema institucional del país es el mismo que tenía Correa desde el año 2008. Los cambios desarrollados por la consulta popular de febrero de 2018 no afectaron mayormente las condiciones en las cuales el presidente ejerce su poder. Por lo tanto, argumentamos que la institucionalidad es la misma con Correa y

20 Estas reformas se dieron en medio de las investigaciones que desembocarían, el 7 de abril de 2020, en una sentencia de primera instancia que declara culpables de cohecho (soborno) en el financiamiento de la campaña electoral de 2013 al expresidente Rafael Correa, al exvicepresidente Jorge Glas y a ocho altos funcionarios de su gobierno y diez empresarios (El Universo 2020).

21 Para un análisis de los sistemas electorales en Ecuador recomendamos al capítulo 5 de Freidenberg y Pachano (2016).

22 Para un análisis de iure de las fortalezas del legislativo recomenzamos Huertas (2018). 
con Moreno. Las grandes diferencias entre uno y otro son el estilo de liderazgo y la situación económica del país que depende fundamentalmente del precio internacional del petróleo (y ambas tributan para afectar la popularidad del presidente). Esquemáticamente se resume en la tabla 6.

Tabla 6. Resumen de argumentos

\begin{tabular}{lccc}
\hline $\begin{array}{l}\text { Poderes } \\
\text { institucionales } \\
\text { (poderes políticos) }\end{array}$ & Poderes contextuales & Estilo de gobierno & Resultados \\
\hline Altos & Alta popularidad. & Con fuerte relación \\
& $\begin{array}{c}\text { Bonanza económica (mayor } \\
\text { parte del tiempo) por aumento } \\
\text { los precios del petróleo }\end{array}$ & $\begin{array}{c}\text { Estabilidad } \\
\text { política }\end{array}$ \\
& $\begin{array}{c}\text { Popularidad variable, pero en } \\
\text { descenso. }\end{array}$ & $\begin{array}{c}\text { Alejado de partido } \\
\text { y con perfiles } \\
\text { tecnócratas }\end{array}$ & Inestabilidad \\
Altos & $\begin{array}{c}\text { Crisis económica por baja de } \\
\text { los precios del petróleo }\end{array}$ & & \\
\hline
\end{tabular}

Brinks et al., (2019) identifica como una fuente de debilidad institucional el incumplimiento de lo prescrito en la norma. Esto puede ocurrir, entre otras razones, porque, el gobierno no tiene la capacidad para hacerlas cumplir. Esto es característico de "leyes aspiracionales" creadas con la esperanza de avanzar en su cumplimiento en el tiempo; o también cuando los encargados de hacer cumplir el mandato institucional son estratégicamente negligentes a la hora de realizar su trabajo por incentivos políticos (Holland 2017; Brinks et al. 2019: 26-27).

En el caso del gobierno de Moreno, aunque no de forma exclusiva, estos elementos han estado permanentemente presentes. Por una parte, la crisis económica ha reducido las capacidades estatales necesarias para cumplir con los amplios compromisos del estado frente a sus ciudadanos, incluidos en la Constitución de 2008 (leyes aspiracionales). Este bajo cumplimiento de las expectativas de la ciudadanía a su vez ha afectado la popularidad del presidente y, con ello, su capacidad de persuadir o presionar a otros actores tanto sociales como políticos de cumplir con las normas estipuladas y más aún con la política pública emitida desde el ejecutivo. A esto se suma, la débil conducción política que ha impedido que el gobierno asegure apoyos, lo que, a su vez, no le ha permitido avanzar con su agenda de reformas económicas manteniendo las débiles capacidades estatales para el cumplimiento con los ya referidos compromisos ciudadanos del gobierno.

Aunque existen claras diferencias en el estilo de gobierno, condiciones económicas y popularidad del presidente, el marco institucional formal, que regula al presidente y los poderes estatales, no ha cambiado. Por lo tanto, es posible 
inferir que un resultado tan disímil entre la administración de Rafael Correa y la de Lenín Moreno es la evidencia de que el marco institucional siempre fue débil. Las instituciones en Correa y Moreno son las mismas, pero dependen del estilo de liderazgo y del contexto económico, particularmente de los precios del petróleo. Contrario al espejismo de estabilidad institucional y política de más de diez años, en realidad se redescubre un escenario político que, disimulado por una década de bonanza económica, una vez que esta se ha agotado desvela, entre protestas, divisiones y elecciones, la persistente debilidad institucional de Ecuador.

\section{REFERENCIAS}

Altman, David, y Rossana Castiglioni. 2008. "Cabinet Determinants of Structural Reforms in Latin America, 1985-2000." The Developing Economies 46(1): 1-25.

Altman, David. 2000. "The Politics of Coalition Formation and Survival in Multiparty Presidential Democracies: The Case of Uruguay, 1989-1999." Party Politics 6(3): 259-83.

Altman, David. 2019. Citizenship and Contemporary Direct Democracy. Cambridge: Cambridge University Press.

Altmann, Philipp. 2020. "Eleven Days in October 2019 - the Indigenous Movement in the Recent Mobilizations in Ecuador." International Journal of Sociology 50(3): 220-26.

Amorim Neto, Octavio. 2006. "The Presidential Calculus Executive Policy Making and Cabinet Formation in the Americas." Comparative Political Studies 39(4): 415-40

Arana, Ignacio. 2016. “¿Cómo Evaluar a los Integrantes de la Élite Política? Una Propuesta Basada en los Presidentes Americanos." Revista Política 54(1): 219-54.

Arévalo, María Inés, y Santiago Basabe-Serrano. 2017. "La Democracia en Ecuador: Déficit Institucional y Conservadurismo Social (1979-2016)." En Políticas Latinoamericana Contemporánea, editado por Godofredo Vidal de la Rosa. México: Universidad Autónoma Metropolitana, 391-418

Asamblea Nacional de Ecuador. Consultas de propuestas y proyectos de ley. https://leyes. asambleanacional.gob.ec/

Barragán, Melany, Angélica Abad, José Rivas, Lara Goyburu, Facundo Cruz, Víctor Tricot, María Barrientos. 2020." América Latina 2019: Vuelta a la Inestabilidad." Iberoamericana 20(73): 205-41.

Banco Mundial. 2020. Datos Ecuador. Disponible en: https://datos.bancomundial.org/pais/ ecuador

Basabe-Serrano, Santiago. 2017. "Las distintas Caras del Presidencialismo: Debate Conceptual y Evidencia Empírica en Dieciocho Países de América Latina." Revista Española de Investigaciones Sociológicas 157: 3-22.

Basabe-Serrano, Santiago. 2018. "Citizenship and Political Parties in Ecuador." En Civil Society and Political Representation in Latin America (2010-2015), editado por Adrián Albala. Springer, 149-65.

Basabe-Serrano, Santiago. 2020. "La Sub Representación de Mujeres en Gabinetes Ministeriales: el Caso Ecuatoriano en Perspectiva Comparada, 1979-2015." Latin American Research Review 55(1): 31-48.

Basabe-Serrano, Santiago, John Polga, y Andrés Mejía. 2018. “Unilateral, Against All Odds. Portafolio Allocations in Ecuador (1979-2015)." En Government Formation and Minister Turnover in Presidential Cabinets: Comparative Analysis in the Americas, editado por Marcelo Camerlo y Cecilia Martínez-Gallardo. London and New York: Routledge, 1-17.

Basabe-Serrano, Santiago, Pachano Simón, Andrés Mejía Costa. 2010. "La democracia inconclusa: Derechos fundamentales, instituciones políticas y rendimientos gubernamentales en Ecuador (1979-2008)." Revista de ciencia política (Santiago), 30(1):65-85. 
BBC News Mundo. 2019. 9 de octubre. "Crisis en Ecuador | Entrevista exclusiva a Lenín Moreno: "La mayoría de los manifestantes venía por mí." BBC Nezws Mundo. Recuperado el 24 de mayo de 2020 de https://www.bbc.com/mundo/noticias-america-latina-49981979

Bidegain, Germán. 2017. "Vicepresidentes en América del Sur: Una Agenda de Investigación." Colombia Internacional 89: 161-90.

Brinks, Daniel M., Steven Levitsky, y Maria Victoria Murillo. 2019. Understanding Institutional Weakness: Power and Design in Latin American Institutions. Cambridge: Cambridge University Press.

Camerlo, Marcelo, y Cecilia Martínez-Gallardo, eds. 2018. Government Formation and Minister Turnover in Presidential Cabinets: Comparative Analysis in the Americas. London and New York: Routledge.

Carreras, Miguel. 2013. "Presidentes Outsiders y Ministros Neófitos: Un Análisis a través del Ejemplo de Fujimori." América Latina Hoy 64: 95-118.

Castro, Raisa. 2019. “¿Las Mujeres Representan a las Mujeres?: Analizando la Asamblea Nacional del Ecuador 2009-2016." Políticas Públicas 12(2): 16-34

Chiasson-LeBel, Thomas. 2019. "Neoliberalism in Ecuador after Correa: A Surprise Turn or According to Economic Elites' Plan?" European Review of Latin American and Caribbean Studies (108): 153-74.

Consejo Nacional Electoral. 2019. Resultados finales elecciones seccionales 2019 y CPCSS. Disponible online: https:/ /app01.cne.gob.ec/resultados2019/

Consulta Mitofsky. 2020. Aprobación de Mandatarios. América y el Mundo. Recuperado el 21 de mayo de 2020 de http:/ /www.consulta.mx/index.php/encuestas-e-investigaciones/el-mundo/item/1329-mandatarios-2020 (21 de mayo de 2020).

Dandoy, Regis. 2019. "Party Strategies and Performances in the 2019 Provincial Elections in Ecuador." Democracias (7): 133-53.

Decreto Ejecutivo No 333, .2018. Disponible online:

https://www.eluniverso.com/sites/default/files/archivos/2018/03/decreto_333_nuevo_ mandato_20180206164520.pdf consultado 15 de mayo de 2020

Decreto Ejecutivo No 883, .2019. Disponible online: https://drive.google.com/file/d/1UVzf74L14GxYON6d78ceZIBCPYzaZy1z/view consultado 10 de abril de 2020

Díaz, Valentín, y Mariela Rosero. 2019, 9 de octubre. “Bombas Lacrimógenas Cayeron en Dos Universidades con Niños; Ministra de Gobierno se disculpa." El Comercio. Recuperado el 24 de mayo de 2020 de https: / / www.elcomercio.com/actualidad/policia-bombas-lacrimogenas-universidades-indigenas.html

El Comercio. 2018, 6 de marzo. "La Asamblea destituye a José Serrano de su cargo de presidente y llama a juicio político a Carlos Baca." Recuperado el 24 de mayo de 2020 de https://www.elcomercio.com/actualidad/asamblea-destitucion-joseserrano-carlospolit-juiciopolitico.html

El Comercio. 2019a, 2 de octubre. "Decreto 883 establece que el alza de las gasolinas extra y ecopaís y del diésel regirá desde el 3 de octubre del 2019." Recuperado el 24 de mayo de 2020 de https://www.elcomercio.com/actualidad/decreto-alza-gasolinas-diesel-subsidios.html

El Comercio. 2019b, 10 de octubre. "Policías recibieron impacto de molotov en el Centro Histórico; un agente sufrió quemaduras en casi todo el cuerpo." Recuperado el 24 de mayo de 2020 de https: / / www.elcomercio.com/actualidad/policia-herido-molotov-quemaduras-movilizaciones.html

El Comercio. 2019c, 7 de octubre. "Manifestantes incendiaron un vehículo blindado de las Fuerzas Armadas." Recuperado el 24 de mayo de 2020 de https://www.elcomercio. $\mathrm{com} /$ video/incendio-blindado-fuerzas-armadas-manifestantes.html

El Comercio. 2019d, 9 de octubre. "Militares retenidos en los páramos de Ecuador durante las protestas." Recuperado el 24 de mayo de 2020 de https:/ /www.elcomercio.com/ actualidad/militares-brigada-patria-retenidos-cotopaxi.html 
El Comercio. 2019e, 14 de noviembre. "Discurso del general Javier Pérez sobre la actuación del Ejército durante las protestas de octubre (11:15)." Recuperado el 24 de mayo de 2020 de https://www.elcomercio.com/video/discurso-general-perez-militares-protestas.html

El Comercio. 2019f, 15 de octubre de 2019. “Juez dicta prisión preventiva de 90 días para prefecta Paola Pabón." Recuperado el 24 de mayo de 2020 de https:/ /www.elcomercio. $\mathrm{com} /$ actualidad/juez-dicta-prision-preventiva-paola.html

El Comercio. 2020a, 1 de febrero. "Juicio político a Diana Atamaint rompió acuerdo legislativo entre Creo y AP". Recuperado el 24 de mayo de 2020 de https:/ / www.elcomercio. com/actualidad/juicio-atamaint-creo-ap-asamblea.html

El Comercio. 2020b, 5 de febrero. "María Alejandra Vicuña deberá cumplir su condena de un año en la cárcel." Recuperado el 24 de mayo de 2020 de https:/ / www.elcomercio. $\mathrm{com} /$ actualidad/corte-nacional-vicuna-condena-carcel.html

El Telégrafo. 2013, 5 de mayo. "La clase baja es la menos favorecida con los subsidios." Recuperado el 24 de mayo de 2020 de https:/ / www.eltelegrafo.com.ec/noticias/economia/8/estado-gasta-3-827-millones-en-subsidios-para-los-combustibles

El Universo. 2017, 24 de mayo. “Lenín Moreno posesiona ministros y cambia la estructura del Ejecutivo." Recuperado el 24 de mayo de 2020 de https: / / www.eluniverso.com/ noticias/2017/05/24/nota/6199201/lenin-moreno-posesiona-ministros-cambia-estructura-ejecutivo

El Universo. 2019a, 13 de octubre. "Armas y estrategias usadas en protestas en Ecuador generan sorpresa en expertos en seguridad." Recuperado el 24 de mayo de 2020 de https://www.eluniverso.com/noticias/2019/10/13/nota/7558556/ecuador-estrategias-armas-artesanales-seguridad-violencia-protestas

El Universo. 2019b, 15 de octubre. “Ocho fallecidos y 1.340 heridos en las protestas en Ecuador, según la Defensoría del Pueblo." Recuperado el 24 de mayo de 2020 de https: / / www.eluniverso.com/noticias/2019/10/15/nota/7560137/ocho-fallecidos-1340-heridos-protestas

El Universo. 2019c, 19 de octubre. "Paola Pabón, Prefecta de Pichincha, fue detenida para investigaciones." Recuperado el 24 de mayo de 2020 de https: / / www.eluniverso.com/ noticias/2019/10/14/nota/7559342/paola-pabon-prefecta-pichincha-detenida

El Universo. 2019d, 25 de diciembre. "Orden judicial permitió a prefecta Paola Pabón salir libre esta madrugada." Recuperado el 24 de mayo de 2020 de https://www.eluniverso.com/noticias/2019/12/25/nota/7664958/orden-judicial-permite-que-prefecta-paola-pabon-salga-casa

El Universo. 2020, 7 de abril. "Tribunal sentencia a 8 años de prisión a Rafael Correa y Jorge Glas como autores mediatos en caso Sobornos." Recuperado el 24 de mayo de 2020 de https://www.eluniverso.com/noticias/2020/04/07/nota/7807251/rafael-correa-culpable-caso-sobornos

Escudero, María C., y Ricardo Gamboa. 2017. Análisis de las Relaciones Ejecutivo-Legislativo: Innovaciones Constitucionales y Mecanismos de Gestión Institucional en Perspectiva Comparada en el marco del Proceso Constituyente. Santiago: Ministerio Secretaría General de la Presidencia.

Fondo Monetario Internacional. 2019a. Comunicado de Prensa 19/72. Recuperado el 24 de mayo de 2020 de https://www.imf.org/es/News/Articles/2019/03/11/ecuadorpr1972-imf-executive-board-approves-eff-for-ecuador

Fondo Monetario Internacional. 2019b. Perspectivas de la economía mundial: Desaceleración mundial de la actividad manufacturera, crecientes barreras comerciales. Washington: FMI

Freidenberg, Flavia, y Simón Pachano. 2016. El Sistema Político Ecuatoriano. Quito: FLACSO Ecuador.

Freidenberg, Flavia y Tomas Dosek. 2016. "Las Reformas Electorales en América Latina (1978-2015)." En Reformas Políticas en América Latina: tendencias y casos, editado por Casas-Zamora Kevin, Marian Vidaurri, Betilde Muñoz-Pogossian, Raquel Chanto. Washington: Secretaría General de la Organización de los Estados Americanos, 25-92. 
Gamavisión. 2019a, 7 de octubre. "Entrevista a Oswaldo Jarrín-Ministro de Defensa del Ecuador." Teleamazonas. Recuperado el 24 de mayo de 2020 de https:/ / www.youtube. com/watch?v=uNZ_S8601-E

Gamavisión. 2019b, 12 de octubre. "Decenas de voluntarios, médicos y paramédicos formaron un cordón afuera de las universidades \#UPS y \#PUCE, para proteger las zonas consideradas puntos de paz". Twitter. Recuperado el 24 de mayo de 2020 de https:/ / twitter.com/Gamavisionecu/status/1183191143640641536

Gamboa, Ricardo, y Sergio Toro. 2018. "The Electoral Connection in Presidential Systems: Non-Legislative Actions inside the Chilean Congress." The Journal of Legislative Studies 24(3): 249-71.

García, Andrés. 2018, 26 de diciembre. "Las funciones de Sonnenholzner: Diálogo, agenda sostenible, atracción de inversiones y coordinación." El Comercio. Recuperado el 24 de mayo de 2020 de https://www.elcomercio.com/actualidad/otto-sonnenholzner-funciones-gobierno-agenda.html

García, Andrés. 2019, 31 de julio. "La Supercom deja de existir este miércoles 31 de julio del 2019." El Comercio. Recuperado el 24 de mayo de 2020 de https://www.elcomercio. com/actualidad/liquidacion-supercom-consejo-informacion-comunicacion.html

GK City. 2019, 3 de octubre. "Bancada de la Revolución Ciudadana pide la destitución de Lenín Moreno." Recuperado el 24 de mayo de 2020 de https:/ gk.city/2019/10/03/ destitucion-lenin-moreno/

González-Bustamante, Bastián, y Alejandro Olivares. 2016. “Cambios de gabinete y supervivencia de los ministros en Chile durante los gobiernos de la Concertación (19902010)." Colombia Internacional 87: 81-108.

Guerrero, Efren. 2018. "Narrativas de la legalidad en el hiperpresidencialismo constitucionalizado ecuatoriano." EUNOMÍA. Revista en Cultura de la Legalidad 14: 175-190

Holland, Alisha C. 2017. Forbearance as Redistribution: The Politics of Informal Welfare in Latin America. Cambridge: Cambridge University Press.

Huertas, Sergio. 2018. “¿Qué tan Fuerte es el Legislativo en Ecuador?: Un Estudio de sus Poderes Constitucionales Desde el Retorno a la Democracia." Políticas Públicas 11(2): 40-57.

Indridason, Indridi H., y Shaun Bowler. 2013. “Determinants of Cabinet Size: Determinants of Cabinet Size." European Journal of Political Research 53(2): 381-403.

Instituto Nacional de Estadística y Censos. 2019. Boletín técnico $N^{\circ}$. ENEMDU. Ecuador: INEC

Jaramillo, Mauricio. 2018. "Partidocracia, autoritarismo y refundación: una lectura de la historia transmisión ecuatoriana del mito del eterno retorno". En Regards actuels sur les régimes autoritaires dans le monde luso-hispanophone: la transmission en question, editado por Émilie Delafosse. Binges: Éditions Orbis Tertius, 65-81.

La Hora. 2006, 22 de noviembre. "Quito pide que la dejen trabajar". Recuperado el 24 de mayo de 2020 de https://lahora.com.ec/noticia/502177/las-autoridades-municipales-no-tienen-previsto-hacer-ningc3ban-pedido-al-gobierno-durante-la-sesic3b3n-solemne-por-las-fiestas-de-quito-que-tendrc3a1-lugar-el-6-de-diciembre-prc3b3ximoesto-se-debe-no-solo-a-que-el-gobierno-termina-sus-funciones-un-mes-despuc3a9ssino-a-que-la-ciudad-quiere-cambiar-su-relacic3b3n-con-los-gobiernos-de-turno-

Marsteintredet, Leiv. 2019. "La Vicepresidencia y los Problemas de la Sucesión Presidencial en América Latina: Viejos y Nuevos Retos para el Presidencialismo." Política y Gobierno 26(1): 117-37.

Marsteintredet, Leiv, y Fredrik Uggla. 2019. "Allies and Traitors: Vice-Presidents in Latin America." Journal of Latin American Studies 51(03): 665-88.

Mejía Acosta, Andrés. 2006. "Crafting Legislative Ghost Coalitions in Ecuador. Informal Institutions and Economic Reform in an Unlikely Case." En Informal Institutions and Democracy: Lessons From Latin America, editado por Gretchen Helmke y Steven Levitsky. Baltimore: Johns Hopkins University Press, 69-85. 
Mejía Acosta, Andrés, y John Polga-Hecimovich. 2011. “Coalition Erosion and Presidential Instability in Ecuador." Latin American Politics and Society 53(2): 87-111.

Meléndez, Carlos, y Paolo Moncagatta. 2017. "Ecuador: Una Década de Correísmo." Revista de ciencia política (Santiago) 37(2): 413-48.

Mieres, Pablo, y Ernesto Pampín. 2015. "La Trayectoria de los Vicepresidentes en los Regímenes Presidencialistas de América." Revista de Estudios Políticos (167): 99-132.

Moncagatta, Paolo, y Ana Emilia Poveda. 2020. «Politización de la ciudadanía y polarización ideológica en Ecuador». En Cultura política de la democracia en Ecuador y en las Américas, 2018/19: Tomándole el pulso a la democracia, editado por Paolo Moncagatta, Arturo Moscoso, Simón Pachano, J. Daniel Montalvo, Elizabeth J. Zechmeister. Ecuador: LAPOP, 79-95.

Olivares, Alejandro, Bastián González, Sergio Toro, Juan Carlos Arellano, Anabel Yanes, José Zurita, Amanda Lopes, Claudio Robelo, Juan Canavesi. 2020. "Nuevos desafíos, enfoques y perspectivas para estudiar élites políticas." Iberoamericana 20(74): 229-259.

Olivares, Alejandro, Mireya Dávila, y Jaime Baeza. 2015. "Los Gabinetes Ministeriales en la Democracia Chilena post-1990: Un Caso de Estabilidad, Continuidad Histórica y Negociación inter-partidaria." Revista DAAPGE 24(15): 7-31.

Ortiz, Richard. 2018. "Los Problemas Estructurales de la Constitución Ecuatoriana de 2008 y el Hiperpresidencialismo Autoritario." Estudios constitucionales 16(2): 527-66.

Pachano, Simón. 1997. "La Caída de Bucaram No Debe Sorprender: Democracia a la Medida." Íconos - Revista de Ciencias Sociales (1): 7-14.

Polga Hecimovich, John. 2010. Políticas, Militares y Ciudadanos: un Análisis de las Caídas Presidenciales en Ecuador, 1997-2005. 1. ed. Quito: Universidad Andina Simón Bolívar.

Primicias. 2019, 13 de octubre. "Gobierno y cúpula indígena inician negociaciones en Quito." Recuperado el 24 de mayo de 2020 de https:/ / www.primicias.ec/noticias/politica/ gobierno-cupula-indigena-inician-negociaciones/

Ramírez, Franklin. 2019. "Las Masas en octubre. Ecuador y las Colisiones de Clase." Nueva Sociedad (284): 15-27.

Ramírez, Franklin (ed.). 2020. Octubre y el Derecho a la Resistencia. Revuelta Popular y Neoliberalismo Autoritario en Ecuador. Buenos Aires: CLACSO-Consejo Latinoamericano de Ciencias Sociales.

Ramírez, Jacques Paul. 2017. “Lo Crudo, lo Cocido y lo Quemado: Etnografía del Proyecto de Ley Orgánica de Movilidad Humana en Ecuador." En Migración, Estado y Políticas: Cambios y Continuidad en América del Sur, editado por Jacques Paul Ramírez. Bolivia: Vicepresidencia del Estado Plurinacional de Bolivia y CELAG, 93-128.

Rodríguez, Javier. 2020. "¿De qué polarización hablamos?" Vozz data + politics. Recuperado el 27 de julio de 2020 de http:/ / thevozz.com/de-que-polarizacion-hablamos /

Sánchez, Francisco, y John Polga-Hecimovich. 2019. “The Tools of Institutional Change under Post-Neoliberalism: Rafael Correa's Ecuador." Journal of Latin American Studies 51(2): 379-408.

Serrafero, Mario. 1999. El Poder y Su Sombra: Los Vicepresidentes. Argentina: Editorial de Belgrano.

Silva, Eduardo. 2015. "Social Movements, Protest, and Policy". Revista Europea de Estudios Latinoamericanos y del Caribe (100):27-39.

Sotomayor, Patricia, y Sergio Huertas. 2017. "Mujeres en Gabinetes Ministeriales. Un Estudio de Ecuador Desde el Retorno a la Democracia (1979-2015)." Política. Revista de Ciencia Política 55(2): 7-32.

Sotomayor, Patricia. 2019. "El Poder Constitucional en América Latina: Hacia una Tipología de las Cortes Constitucionales de la Región." OPERA (24): 5-26.

Teleamazonas. 2019, 3 de octubre. "Dirigentes de transportistas encabezan acciones de protestas." Recuperado el 24 de mayo de 2020 de http: / / www.teleamazonas.com/2019/10 / dirigentes-de-transportistas-encabezan-acciones-de-protestas / 
The Global Competitiveness Report. 2019. World Economic Forum. Recuperado el 21 de mayo de 2020 de http://www3.weforum.org/docs/WEF_TheGlobalCompetitivenessReport2019.pdf

Toro, Sergio. 2007. “Conducta Legislativa ante las Iniciativas del Ejecutivo: Unidad de los Bloques Políticos en Chile." Revista de ciencia política (Santiago) 27(1): 23-41.

Valencia, José. 2019. Canciller de Ecuador: "Es evidente que existe un plan concebido." DW. Recuperado el 24 de mayo de 2020 de https://www.dw.com/embed/480/av50743417

Vélez, Roger. 2019a, 29 de enero. "19 asambleístas son investigados por la Fiscalía por cobros indebidos." El Comercio. Recuperado el 24 de mayo de 2020 de https: / / www.elcomercio.com/actualidad/asambleistas-investigados-fiscalia-cobros-denuncias.html

Vélez, Roger. 2019b, 8 de febrero. "En menos de tres meses, otra asambleísta pierde su cargo." El Comercio. Recuperado el 24 de mayo de 2020 de https://www.elcomercio.com/ actualidad/ana-galarza-destitucion-asambleistas-denuncias.html

Vélez, Roger. 2019c, 14 de mayo. "BIN, BADI y CREO anuncian respaldo a AP para Presidencia de la Asamblea." El Comercio. Recuperado el 24 de mayo de 2020 de https: / www. elcomercio.com/actualidad/creo-respaldo-presidencia-asamblea-ecuador.html

Recibido: 26 de mayo de 2020

Aceptado: 20 de julio de 2020

Alejandro Olivares L. Profesor del Departamento de Sociología y Ciencia Política de la Universidad Católica de Temuco, Chile. Magíster en Ciencia Política y Doctor en Ciencias Sociales por la Universidad de Chile. Entre marzo de 2018 y marzo de 2020 se desempeñó como profesor visitante de la Facultad Latinoamericana de Ciencias Sociales (FLACSO) en Quito, Ecuador. Correo electrónico: alejandro.olivares@uct.cl

Pablo Medina P. Investigador del programa de Doctorado en Ciencia Política de la Facultad de Ciencias Sociales en Ecuador (FLACSO) y docente de la Pontificia Universidad Católica del Ecuador. Magíster en Relaciones Internacionales por la Universidad Andina Simón Bolívar Ecuador, Master en Administración Pública por la Universidad Católica de Lovaina. Candidato a Doctor en Ciencia Política por FLACSO Ecuador. Correo electrónico: mppablofl@flacso.edu.ec 


\section{ANEXO}

Ministros de Moreno 2017-2019

\begin{tabular}{|c|c|c|c|c|}
\hline Ministerio & Ministro & Asume & Deja & Partido \\
\hline Telecomunicaciones & Andrés Michelena & $04 / 06 / 2019$ & en el cargo & Independiente \\
\hline $\begin{array}{l}\text { Transporte y Obras } \\
\text { Públicas }\end{array}$ & Gabriel Martínez & $21 / 08 / 2019$ & en el cargo & Independiente \\
\hline Defensa & Oswaldo Jarrín & $27 / 04 / 2018$ & en el cargo & Independiente \\
\hline $\begin{array}{l}\text { Desarrollo Urbano y } \\
\text { Vivienda }\end{array}$ & Guido Macchiavello & 03/07/2019 & en el cargo & Independiente \\
\hline $\begin{array}{l}\text { Inclusión Económica } \\
\text { y Social }\end{array}$ & Iván Granda & $18 / 10 / 2019$ & en el cargo & Ruptura 25 \\
\hline Producción & Iván Ontaneda Berrú & $27 / 06 / 2019$ & en el cargo & Independiente \\
\hline Relaciones Exteriores & José Valencia & $12 / 06 / 2018$ & en el cargo & Independiente \\
\hline Cultura y Patrimonio & Juan Fernando Velasco & $27 / 06 / 2019$ & en el cargo & Independiente \\
\hline Gobierno & María Paula Romo & $31 / 08 / 2018$ & en el cargo & Ruptura 25 \\
\hline Educación & Monserrat Creamer & $27 / 06 / 2019$ & en el cargo & Independiente \\
\hline Economía y Finanzas & Richard Martínez & $14 / 05 / 2018$ & en el cargo & Independiente \\
\hline $\begin{array}{l}\text { Agricultura y } \\
\text { Ganadería }\end{array}$ & Xavier Lazo & $21 / 08 / 2018$ & en el cargo & Independiente \\
\hline Turismo & Rosa Prado & $03 / 12 / 2018$ & en el cargo & Independiente \\
\hline Trabajo & Andrés Madero & 03/07/2019 & En el cargo & $\begin{array}{l}\text { Mov. Centro } \\
\text { Democrático }\end{array}$ \\
\hline Salud Pública & Catalina Andramuño & $18 / 10 / 2019$ & En el cargo & Independiente \\
\hline Energía & José Agusto Briones & $19 / 11 / 2019$ & En el cargo & Independiente \\
\hline Ambiente y Agua & Raúl Ledesma Huerta & $19 / 08 / 2019$ & En el cargo & $\begin{array}{l}\text { Mov. Centro } \\
\text { Democrático }\end{array}$ \\
\hline Energía & Carlos Pérez García & $24 / 05 / 2017$ & $19 / 11 / 2019$ & Independiente \\
\hline $\begin{array}{l}\text { Inclusión Económica } \\
\text { y Social }\end{array}$ & Berenice Cordero Molina & $13 / 12 / 2017$ & $18 / 10 / 2019$ & Independiente \\
\hline $\begin{array}{l}\text { Transporte y Obras } \\
\text { Públicas }\end{array}$ & Aurelio Hidalgo Zavala & $20 / 09 / 2018$ & $21 / 08 / 2019$ & Independiente \\
\hline Ambiente y Agua & Marcelo Mata Guerrero & $03 / 12 / 2018$ & $19 / 08 / 2019$ & Independiente \\
\hline Salud Pública & Verónica Espinosa & $24 / 05 / 2017$ & 03/07/2019 & Independiente \\
\hline $\begin{array}{l}\text { Desarrollo Urbano y } \\
\text { Vivienda }\end{array}$ & Xavier Torres Correa & $17 / 04 / 2018$ & 03/07/2019 & Independiente \\
\hline Educación & Milton Luna Tamayo & $03 / 12 / 2018$ & $27 / 06 / 2019$ & Independiente \\
\hline Cultura y Patrimonio & Raúl Pérez Torres & $24 / 05 / 2017$ & $27 / 06 / 2019$ & Independiente \\
\hline Producción & Pablo Campana Sáenz & $14 / 01 / 2019$ & $20 / 06 / 2019$ & Independiente \\
\hline Telecomunicaciones & $\begin{array}{l}\text { Guillermo León } \\
\text { Santacruz }\end{array}$ & $24 / 05 / 2017$ & $13 / 03 / 2019$ & Independiente \\
\hline Trabajo & Raúl Ledesma Huerta & $24 / 05 / 2017$ & $11 / 01 / 2019$ & $\begin{array}{l}\text { Mov. Centro } \\
\text { Democrático }\end{array}$ \\
\hline
\end{tabular}




\begin{tabular}{|c|c|c|c|c|}
\hline Ministerio & Ministro & Asume & Deja & Partido \\
\hline Turismo & Enrique Ponce de León & $24 / 05 / 2017$ & $03 / 12 / 2018$ & Independiente \\
\hline Educación & Fánder Falconí Benítez & $24 / 05 / 2017$ & $23 / 11 / 2018$ & Alianza PAIS \\
\hline Gobierno & Mauro Toscanini Segale & $27 / 04 / 2018$ & $31 / 08 / 2018$ & Independiente \\
\hline Producción & Eva García Fabre & $24 / 05 / 2017$ & $23 / 08 / 2018$ & Independiente \\
\hline Ambiente y Agua & Tarsicio Granizo Tamayo & $24 / 05 / 2017$ & $23 / 08 / 2018$ & Independiente \\
\hline $\begin{array}{l}\text { Agricultura y } \\
\text { Ganadería }\end{array}$ & Rubén Flores Agreda & $18 / 10 / 2017$ & $13 / 08 / 2018$ & Independiente \\
\hline Relaciones Exteriores & María Fernanda Espinosa & $24 / 05 / 2017$ & $12 / 06 / 2018$ & Alianza PAIS \\
\hline $\begin{array}{l}\text { Transporte y Obras } \\
\text { Públicas }\end{array}$ & Paúl Granda López & $24 / 05 / 2017$ & $16 / 05 / 2018$ & Alianza PAIS \\
\hline Economía y Finanzas & $\begin{array}{l}\text { María Elsa Viteri } \\
\text { Acaiturri }\end{array}$ & $06 / 03 / 2018$ & $14 / 05 / 2018$ & Independiente \\
\hline Gobierno & César Navas Vera & $24 / 05 / 2017$ & $27 / 04 / 2018$ & Independiente \\
\hline Defensa & Patricio Zambrano & $15 / 09 / 2017$ & $27 / 04 / 2018$ & $\begin{array}{l}\text { Partido } \\
\text { Socialista }\end{array}$ \\
\hline Economía y Finanzas & Carlos de la Torre Muñoz & $24 / 05 / 2017$ & $06 / 03 / 2018$ & Independiente \\
\hline $\begin{array}{l}\text { Desarrollo Urbano y } \\
\text { Vivienda }\end{array}$ & María Alejandra Vicuña & $24 / 05 / 2017$ & $06 / 01 / 2018$ & Alianza PAIS \\
\hline $\begin{array}{l}\text { Inclusión Económica } \\
\text { y Social }\end{array}$ & Iván Espinel & $24 / 05 / 2017$ & $13 / 12 / 2017$ & $\begin{array}{c}\text { Fuerza } \\
\text { Compromiso } \\
\text { Social }\end{array}$ \\
\hline $\begin{array}{l}\text { Agricultura y } \\
\text { Ganadería }\end{array}$ & Vanessa Cordero & $24 / 05 / 2017$ & $18 / 10 / 2017$ & Independiente \\
\hline Defensa & Miguel Carvajal & $24 / 05 / 2017$ & $15 / 09 / 2017$ & Alianza PAIS \\
\hline
\end{tabular}


